\title{
Simulated Polarimetric Fields of Ice Vapor Growth Using the Adaptive Habit Model. Part I: Large-Eddy Simulations ${ }^{\mathscr{Q}}$
}

\author{
KARA J. SULIA \\ Atmospheric Sciences Research Center, University at Albany, State University of New York, Albany, New York \\ MATTHEW R. KUMJIAN \\ Department of Meteorology and Atmospheric Science, The Pennsylvania State University, University Park, Pennsylvania
}

(Manuscript received 15 February 2016, in final form 3 March 2017)

\begin{abstract}
The bulk adaptive habit model (AHM) explicitly predicts ice particle aspect ratio, improving the representation of microphysical processes and properties, including ice-liquid-phase partitioning. With the unique ability to predict ice particle shape and density, the AHM is combined with an offline forward operator to produce fields of simulated polarimetric variables. An evaluation of AHM-forward-simulated dualpolarization radar signatures in an idealized Arctic mixed-phase cloud is presented. Interpretations of those signatures are provided through microphysical model output using the large-eddy simulation mode of the Weather Research and Forecasting Model.

Vapor-grown ice properties are associated with distinct observable signatures in polarimetric radar variables, with clear sensitivities to the simulated ice particle properties, including ice number, size, and distribution shape. In contrast, the liquid droplet number has little influence on both polarimetric and microphysical variables in the case presented herein. Polarimetric quantities are sensitive to the dominating crystal habit type in a volume, with enhancements for aspect ratios much lower or higher than unity. This synthesis of a microphysical model and a polarimetric forward simulator is a first step in the evaluation of detailed AHM microphysics.
\end{abstract}

\section{Introduction}

Developing an understanding of cloud processes is an ongoing goal within the cloud physics community. Model parameterizations are constantly improving in efforts to better represent warm- (e.g., Morrison and Grabowski 2008; Kogan and Belochitski 2012), cold- (e.g., Khvorostyanov and Sassen 1998; Heymsfield et al. 2007), and mixed-phase clouds (e.g., Thompson et al. 2008; Harrington et al. 2013a; Milbrandt and Morrison 2013).

With ever-increasing computing power, highresolution regional model simulations are more prevalent (e.g., Lean et al. 2008; Weisman et al. 2008). As models move toward higher resolution, appropriately representing microphysics has become increasingly

Supplemental information related to this paper is available at the Journals Online website: http://dx.doi.org/10.1175/ MWR-D-16-0061.s1.

Corresponding author e-mail: Kara J. Sulia, ksulia@albany.edu important. The parameterization of mixed-phase microphysics is especially challenging as the evolutions of liquid and ice are mutually dependent and sensitive to ice number concentration and particle habit evolution (e.g., Harrington et al. 1999; Morrison et al. 2005; Fridlind et al. 2007; Avramov and Harrington 2010; Korolev and Isaac 2003; Sulia and Harrington 2011; Sulia et al. 2013, 2014). A variety of parameterizations have been developed to help understand ice depositional growth and other mixed-phase microphysical interactions and their effects on cloud evolution. For example, the sensitivity to ice number concentration depends on currently available ice nucleation parameterizations (e.g., Meyers et al. 1992), in which the combined modes of deposition and condensation freezing are derived from laboratory data. Others follow a more detailed approach wherein ice nucleation is a function of temperature and aerosol size distribution (DeMott et al. 2010). Beyond nucleation, Saleeby and Cotton (2008), Mitchell and Heymsfield (2005), and Milbrandt and Morrison (2013) offer examples of recently improved 
parameterizations for riming, aggregation, and graupel, respectively, all of which are sensitive to and impact the available liquid and ice masses and precipitation rates. Moreover, ice deposition rates can at times affect liquid dissipation rates for spherical (Korolev and Isaac 2003) and nonspherical ice crystals (Sulia and Harrington 2011). Harrington et al. (2013a) use the concepts from Chen and Lamb (1994) to build a comprehensive ice aspect ratio $(\phi)$ evolving bulk scheme that improves the calculation of ice depositional growth rates. This parameterization is developed so that particle properties are predicted along a continuum rather than the traditional method of predicting discrete hydrometeor types. Evaluating the parameter space of mixed-phase cloud microphysics as a function of particle properties (e.g., shape, density, size distribution) as they relate to the liquid-ice-phase partitioning is crucial to understanding the nature of these clouds.

Understanding microphysical processes is not only critical for the improvement of physics within research and forecasting models (e.g., Hall 1980; Baker 1997; Hong et al. 2004; Fovell and Su 2007; Morrison et al. 2009) but also for accurately interpreting observational data (e.g., Colle and Mass 2000; Kubar et al. 2009). Also useful for understanding observed microphysical processes are dual-polarization (dual-pol) radar data (e.g., Brandes et al. 1995; Zrnić and Ryzhkov 1999; Vivekanandan et al. 1999; Kumjian 2013a,b,c). Unlike traditional single-polarization Doppler radars that transmit electromagnetic waves at only one polarization (horizontal or vertical) at one time, dual-pol radars transmit horizontally and vertically polarized waves alternately or simultaneously. The received signals can be compared to produce a number of useful quantities that provide information on the properties of particles in the sampling volume, including their general anisotropy $(\phi)$, concentration and size distribution, canting (wobbling), and diversity in shape, orientation, and density, all of which are useful for identifying a variety of hydrometeor species, growth characteristics, and microphysical processes (e.g., Zrnić and Ryzhkov 1999; Ryzhkov et al. 2005; Kumjian 2013a,b,c). Since the 1950s, radar meteorologists have used radar polarimetry to better understand cloud and precipitation processes and quantify precipitation [see Browne and Robinson (1952), Hunter (1954), Newell et al. (1955), Wexler (1955), and summarized in Kumjian (2013a)]. However, the National Weather Service (NWS) has only recently (June 2013) completed upgrades to its network of WSR-88Ds, establishing a comprehensive suite of open-access dualpol radar data available to a broader community, including cloud model users and developers. Hence, using dual-pol observations to evaluate modeled microphysical processes and particle properties is a relatively new endeavor, with growing interest in simulating fields of dualpol radar variables from model output (e.g., Jung et al. 2008; Ryzhkov et al. 2011; Kumjian et al. 2014).

Forward-simulated dual-pol radar variables require information on particle shape, orientation, and effective density. Whereas empirical data have established the liquid drop shape as a function of size (e.g., Thurai and Bringi 2005), this approach becomes more complicated for frozen hydrometeors. Hail, graupel, aggregates, and ice pellets are typically quasi spherical (though with varying densities), but pristine ice crystals, such as plates, columns, sectors, needles, and dendrites, are highly nonspherical. Most current microphysical parameterizations common in research and forecasting models assume spherical pristine ice particles using an equivalent volume method with a fixed density (e.g., Lin et al. 1983; Reisner et al. 1998; Thompson et al. 2004) or assign the particle shape a priori according to temperature (e.g., Koenig 1971; Walko et al. 1995; Woods et al. 2007; Thompson et al. 2008) and employ a massdimensional relationship. Although these methods may be appropriate in specific cases and for capturing properties such as mass, these methods do not allow for the evolution of particle shape and hence are unable to capture the detailed growth and advective history of these particles. This deficiency feeds back into predictions of liquid and ice masses, cloud thickness, ice fall velocity and sedimentation (Harrington et al. 2013b; Sulia et al. 2014); collection efficiency (Ono 1969; Hall 1980; Jensen and Harrington 2015); optical depth and scattering properties (e.g., Takano and Liou 1989; Key et al. 2002); and others. To exploit the information available from dual-pol radars, methods appropriately representing particle shape and density are required.

The new bulk adaptive habit model (AHM; Harrington et al. 2013a,b), in which the aspect ratio and density are explicitly predicted for vapor growth, is used herein. Whereas other methods typically diagnose a particle shape or density according to the environment, the AHM tracks the growth history of a bulk ice population, which allows for a smooth transition of particle habit across different growth regimes. This paper provides a presentation of basic forward-simulated dual-pol signatures produced using the AHM. The AHM-simulated dual-pol quantities are then compared with microphysical output parameters (e.g., ice and liquid mass mixing ratios, ice density, aspect ratio, ice number) using the large-eddy simulation (LES) mode of the WRF Model (WRF-LES). As discussed below, the LES framework and the simulated case are chosen because of their relative simplicity. Model results can be interpreted without complexities, such as multiple 

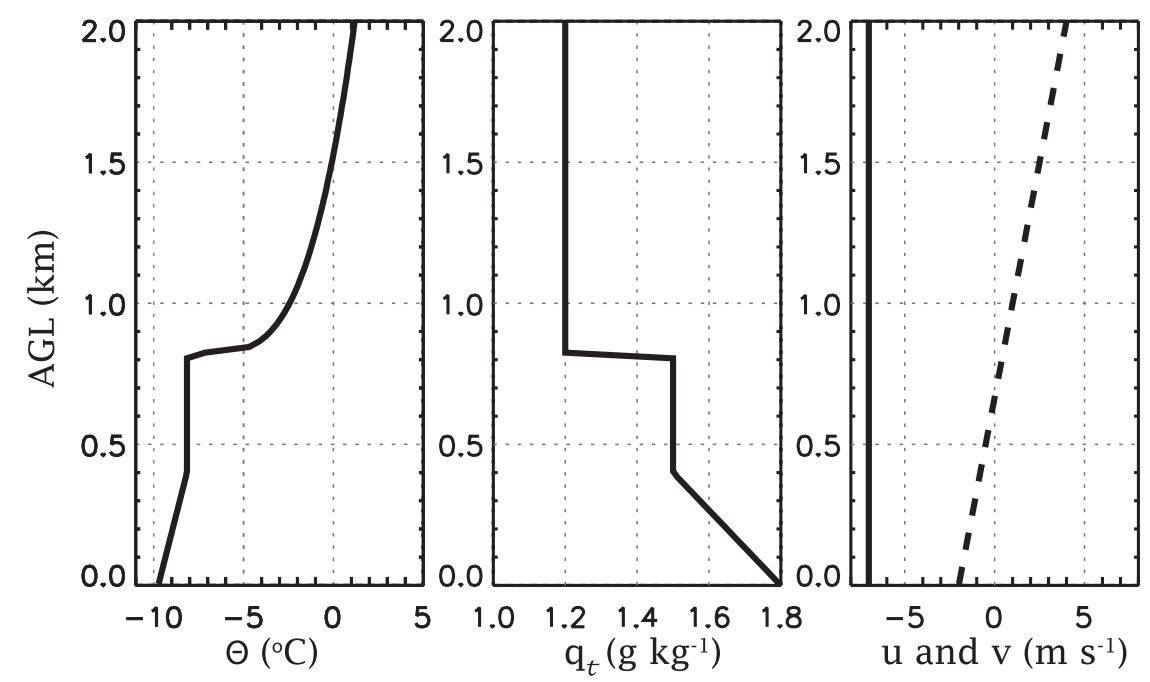

FIG. 1. Initialization vertical profiles above ground level (AGL) of (left) potential temperature $\Theta$, (middle) total water mixing ratio $q_{t}$, and (right) horizontal wind speeds $u$ (solid) and $v$ (dashed) for an idealized shallow Arctic stratus.

hydrometeor types and abruptly evolving flow fields typical of more complicated events. This approach allows for analyses of underlying microphysical processes that affect simulated dual-pol variables within a simplified framework. Moreover, because detailed microphysical data are typically unavailable through in situ or remote sensing retrievals outside of field campaigns, this work provides an opportunity to explore simulated dual-pol signatures with model output. A basis for how models that predict particle properties can be used in combination with dual-pol radars is established. Though the work presented here is idealized, Sulia and Kumjian (2017, hereafter Part II) provide a specific case study to compare simulated and observed radar data.

\section{Model description}

Numerical simulations of an idealized, shallow Arctic stratocumulus are completed using WRF-LES version 3.6 .1 (e.g., Skamarock et al. 2008; Yamaguchi and Feingold 2012). The LES setup allows for resolved turbulent kinetic energy (TKE) and turbulent heat and moisture transport and captures a portion of the inertial subrange. Subgrid-scale mixing is determined from a 1.5-order TKE closure, boundaries are horizontally periodic, advection is monotonic, and the domain is capped with a rigid lid with Rayleigh damping applied to the upper $250 \mathrm{~m}$. The surface layer physics uses MoninObukhov theory, and the longwave (LW) and the shortwave radiative fluxes are determined from the Rapid Radiative Transfer Model (RRTM; Mlawer et al.
1997) and the RRTM for GCMs (RRTMG; Oreopoulos and Barker 1999), respectively.

The simulated case involves a shallow Arctic stratus observed on 26 April 2008 during the Indirect and SemiDirect Aerosol Campaign (ISDAC; McFarquhar et al. 2011) in Barrow, Alaska. The model is initialized and forced with the ideal sounding from the ISDAC intercomparison (Fig. 1) detailed in appendix A of Ovchinnikov et al. (2014), where model forcing is provided by large-scale subsidence. The model dynamic spinup time is $4 \mathrm{~h}$ without ice, and the domain dimensions are $3.2 \mathrm{~km}$ in the horizontal and $2.0 \mathrm{~km}$ in the vertical. The horizontal grid spacing is $50 \mathrm{~m}$, and the vertical grid spacing is defined by mass-based coordinates and ranges from approximately 9 to $11 \mathrm{~m}$. As discussed in Ovchinnikov et al. (2014), the 26 April case was a persistent stratiform mixed-phase cloud deck decoupled from the surface. The case contained light precipitation composed primarily of pristine dendrites without riming or drizzle and with no discernible aggregation. Because the cloud deck persisted in an environment containing pristine ice crystals, it is ideal for analyses of vapor growth using the AHM. Moreover, this case was chosen for its simplicity to easily examine typical simulated microphysical and dual-pol signatures of vapor growth without other detailed microphysical or dynamical processes.

The microphysical scheme used is the aforementioned AHM (Harrington et al. 2013a,b; Sulia et al. 2013, 2014; Jensen and Harrington 2015), which predicts the mass mixing ratio for liquid cloud droplets $q_{c}$, which are held at a relatively constant concentration of $N_{c}=200 \mathrm{~cm}^{-3}$ 
unless otherwise indicated. The model also predicts mass and number mixing ratios for rain $\left(q_{r}\right.$ and $\left.n_{r}\right)$ and snow ( $q_{s}$ and $n_{s}$, respectively), where $n_{r}$ and $n_{s}$ are related to the slope and intercept parameters assuming an exponential distribution (for details see Morrison et al. 2009, 2012). Note that "rain" in this case refers to larger liquid droplets that experience processes such as collection but do not necessarily reach sizes typical of raindrops. Thus, only results of the total liquid mixing ratio $q_{l}$ containing both $q_{c}$ and $q_{r}$ are presented.

Snow $\left(q_{s}\right.$ and $\left.n_{s}\right)$ is an aggregate category only, contains no monomer particles, and is separate from ice $\left(q_{i}\right)$. Ice crystals become snow only through aggregation. The ice-to-snow autoconversion threshold method is used only to determine whether ice crystals aggregate. Traditional aggregation methods (see Passarelli 1978; Reisner et al. 1998; Morrison et al. 2009) are then assumed to determine the ice-ice aggregation rate of forming snow once the autoconversion threshold is met; the ice that does not aggregate remains as $q_{i}$. Snow (aggregates) can also self-collect (snow-snow aggregation), but accretion of ice by snow (ice-snow aggregation) is not considered at this point. Ice properties are then recalculated to account for the loss of mass and number to snow, and the newly formed aggregates are assumed to be spheres with a density of $\rho_{s}=100$ $\mathrm{kg} \mathrm{m}^{-3}$. Hence, $q_{i}$ contains only monomer crystals, and $q_{s}$ contains only aggregates. The traditional aggregation is assumed because an aggregation method specific to the AHM has not yet been developed; however, aggregation is negligible for this shallow Arctic stratocumulus.

Ice mass $q_{i}$, number $n_{i}$, and axis-length-weighted spheroidal-volume $\left(a_{v}\right.$ and $\left.c_{v}\right)$ mixing ratios follow Harrington et al. (2013a), Morrison et al. (2016), and Jensen et al. (2017), respectively, where $n_{i}$ is determined according to a modified gamma distribution of the $a$ axis. Cloud ice axis lengths $a$ and $c$ represent the basal and prism face half-lengths, respectively. Although computations of $a$ and $c$ are performed in units of length mixing ratio $\left(\mathrm{m} \mathrm{kg}^{-1}\right)$, these parameters are converted to volume mixing ratios, that is, $a_{v}=\left(a_{n}^{2} c_{n}\right) \nu n_{i}$ and $c_{v}=\left(c_{n}^{2} a_{n}\right) \nu n_{i}\left(\mathrm{~m}^{3} \mathrm{~kg}^{-1}\right)$, respectively, where $\nu$ is the shape of the distribution of particles, and $a_{n}=a /\left(\nu n_{i}\right)$ and $c_{n}=c /\left(\nu n_{i}\right)$ are the distribution characteristic $a$ - and $c$-axis lengths $(\mathrm{m})$, respectively. This method ensures density conservation during advection. Ice nucleation follows from the ISDAC intercomparison (Ovchinnikov et al. 2014), only activating when ice supersaturation reaches $5 \%$ and at temperatures $\leq-5^{\circ} \mathrm{C}$ following the 4-h dynamic spinup. Ice is activated simply by relaxing the ice number mixing ratio $n_{i}$ to a steady state with a maximum prescribed value, which is $N_{i}=1 \mathrm{~L}^{-1}$ (unless otherwise noted) based on measurements performed during ISDAC (e.g., McFarquhar et al. 2011; Jackson et al. 2012; Ovchinnikov et al. 2014).

Although this idealized setup will not necessarily simulate the evolution of this case, the purpose of this study is to determine the model's ability to produce vapor-grown microphysical signatures. This work provides a basis for more complex case studies, where dual-pol signatures are complicated by other processes. More realistic simulations will be explored in Part II.

\section{a. The adaptive habit model}

The depositional growth of ice crystals depends on the local temperature and saturation, and the existing particle shape, size, and density, all of which evolve nonlinearly (Sulia and Harrington 2011). The AHM employs crystal growth theory and tracks the growth history of the bulk parameters needed to predict ice $\phi$, allowing for an effective means of evolving particle shape and mass in a physically consistent manner. This tracking method is required to accurately predict the ice and liquid water contents in mixed-phase clouds (Harrington et al. 2013a,b). The method has been derived from and validated against a detailed bin ice growth method (Harrington et al. 2013b), which stems from Chen and Lamb (1994) and compares well to wind-tunnel laboratory-grown particles (Fukuta and Takahashi 1999). The microphysical method was then tested on an Eulerian grid within a two-dimensional kinematic model (Sulia et al. 2013). The dynamical impacts of the adaptive habit approach were explored within WRF-LES (Sulia et al. 2014), indicating the indirect effect of crystal habit growth on the dynamic collapse of mixed-phase clouds.

Although the AHM has been tested for depositional growth, it does not yet include the more complex microphysical processes needed for universal cloud applications. Jensen and Harrington (2015) developed riming for the AHM, but the parameterization remains in the testing phase and so is neglected here; hence, graupel is excluded. Although a traditional aggregation approach is employed, aggregation is limited in the present case and so is not explored in detail. Furthermore, whereas the bin version of the AHM has been modified for ice growth within conditions subsaturated with respect to liquid (Zhang and Harrington 2014), this modification has not yet been parameterized within a bulk framework and so ice is assumed to grow and sublimate as traditionally parameterized within the AHM at liquid subsaturation. Despite these shortcomings, the AHM remains valuable because it can predict depositional growth and habit evolution in a physically consistent manner. Because the AHM explicitly predicts particle 
properties, such as ice shape and density, it is an attractive choice for simulating dual-pol radar variables.

\section{b. Radar scattering calculations}

A dual-pol forward operator must be applied to simulate radar signatures from microphysical model output. The forward operator follows the work of Ryzhkov et al. (2011), who employed a Rayleigh-Gans scattering approximation for snow crystals owing to their small electromagnetic size compared to the illuminating radar wavelength. A $6^{\circ}$-simulated antenna elevation angle is assumed, and a wavelength of $3.2 \mathrm{~cm}$ ( $\mathrm{X}$ band) is used. Note that in cases of very large and thin pristine snow crystals the Rayleigh-Gans approximation at $\mathrm{X}$ band may produce inaccurate results. As shown by $\mathrm{Lu}$ et al. (2013), constructive (destructive) interference of finite scattering elements within the complex geometry of a horizontally aligned ice crystal affects the internal electric field strength and thus leads to an enhancement (reduction) in the horizontally (vertically) polarized components of the backscattered radiation. Without information on the complex morphology of the simulated crystals, the uniformly filled spheroid assumption used herein is likely more consistent with the actual model output. This approach has been used with success in previous studies employing such calculations for longwavelength radars (e.g., Jung et al. 2008; Ryzhkov et al. 2011; Kennedy and Rutledge 2011; Andrić et al. 2013; Bechini et al. 2013). For higher-frequency radars, more sophisticated scattering calculations are required; the scattering formulas used herein are invalid for the shorter wavelengths typical of cloud radars. Simulating shorter wavelengths requires employing other methods that could introduce a number of other assumptions and uncertainties. ISDAC National Research Council Airborne $\mathrm{W}$ - and X-band (NAWX) radar observations (at the approximate time of the sounding used to initialize and nudge the model) reveal $\mathrm{X}$-band reflectivity values from approximately -30 to $5 \mathrm{~dB} Z$. The radar system's lower limit is about $-30 \mathrm{~dB} Z$, where instances occur with steady signatures from approximately -30 to $-10 \mathrm{~dB} Z$ (https://dis.arm.gov/campaigns/isdac; see online supplemental material), which are values expected for pristine particles. Oue et al. (2015) also indicate reflectivities as low as $-15 \mathrm{~dB} Z$ for the DOE X-band scanning precipitation radar on 7 December 2013. Although values simulated herein fall outside the typical range of X-band radar detection, the forward-simulated dual-pol quantities are considered reasonable, and the "fingerprints" remain useful for the illustrative purposes of this study.

Computation of the complex scattering amplitudes requires knowledge of the size, shape (aspect ratio), composition, and fall behavior of the hydrometeors. The
AHM explicitly provides the ice crystal particle size and aspect ratio bulk distributions. The particle $\phi$ determines the shape factor in the computation of the scattering amplitudes. The ice crystal effective density $\rho_{i}$, that is predicted and evolved within the model, affects the dielectric constant (which is also a function of particle temperature) and the particle size distribution slope parameter. Fall behavior is based on empirical studies of natural crystals, as summarized in Ryzhkov et al. (2011). From these complex scattering amplitudes, dual-pol radar variables, including reflectivity factor at horizontal polarization $Z_{\mathrm{H}}$, differential reflectivity $Z_{\mathrm{DR}}$, correlation coefficient $\rho_{\mathrm{hv}}$, linear depolarization ratio $L_{\mathrm{DR}}$, differential propagation phase shift $\Phi_{\mathrm{DP}}$, and specific differential phase $K_{\mathrm{DP}}$ are computed. For a more complete description of these dual-pol radar variables, see textbooks by Doviak and Zrnić (1993) and Bringi and Chandrasekar (2001), or review articles by Ryzhkov et al. (2005), Chandrasekar et al. (2013), and Kumjian (2013a,b,c, and references therein). A brief description of the variables is provided here:

- The reflectivity factor at horizontal polarization $Z_{\mathrm{H}}$ is related to the received power backscattered from a collection of particles within the radar sampling volume and is dependent on the size, concentration, and particle dielectric constant, which is a function of particle density and composition.

- Differential reflectivity $Z_{\mathrm{DR}}$ is the difference between $Z_{\mathrm{H}}$ and the reflectivity factor at vertical polarization $Z_{\mathrm{V}}$ in logarithmic units. In addition, $Z_{\mathrm{DR}}$ is a measure of the reflectivity-weighted shape of a collection of particles in the radar sampling volume and is dependent on the shape, density, and composition of particles. The magnitude of $Z_{\mathrm{DR}}$ increases for aspect ratios different from one (depending upon canting and orientation), decreases toward $0 \mathrm{~dB}$ for low-density or spherical particles, and is independent of hydrometeor concentration (except insofar as the mean $Z_{\mathrm{DR}}$ is determined by the reflectivity-weighted mean $\phi$ of particles within a volume). While wobbling is not simulated in the AHM, a distribution of canting angles is imposed as a proxy for wobbling in the forward simulator.

- Correlation coefficient $\rho_{\mathrm{hv}}$ is a measure of the variability of scattering properties within the radar sampling volume, including particle shape, orientation angle, and composition (complex dielectric constant), and is not dependent on concentration. In general, values of $\rho_{\mathrm{hv}}$ will be near unity for a homogenous mixture of hydrometeors (e.g., pure rain, pure snow, etc.), but will decrease with increasing particle heterogeneity.

- Linear depolarization ratio $L_{\mathrm{DR}}$ is the ratio of the magnitude of the depolarized component of the 
backscattered signal to the copolar component. Note that $L_{\mathrm{DR}}$ increases for irregularly shaped particles that are canted with respect to the incident wave polarization, tends to be controlled by the dispersion of canting angles, and is not dependent on concentration; $L_{\mathrm{DR}}$ is unavailable from WSR-88Ds.

- A differential propagation phase shift $\Phi_{\mathrm{DP}}$ occurs when an electromagnetic wave propagating through a population of hydrometeors experiences a shift in phase. Asymmetric particles will result in a $\Phi_{\mathrm{DP}}$. The value of $\Phi_{\mathrm{DP}}$ is proportional to the concentration of hydrometeors and increases with increasing particle size, dielectric constant, and anisotropy.

- Specific differential phase $K_{\mathrm{DP}}$ is half of the range derivative of the propagation phase shift $\Phi_{\mathrm{DP}}$ and is the amount of differential phase shift per unit distance in the radial direction. The value of $K_{\mathrm{DP}}$ is dependent on concentration, size, and composition and only responds to nonspherical particles. Because $K_{\mathrm{DP}}$ and $\Phi_{\mathrm{DP}}$ signatures can be interpreted similarly, only $K_{\mathrm{DP}}$ is shown for brevity.

Integration over multiple hydrometeors in a volume is required for the forward operator. Thus, the bulk ice population is separated into 100 size bins of equal width. The first (last) bin contains the smallest (largest) equivalent volume radius in the ice population per time step, where the smallest (largest) bin edges are constrained to 0 and $30 \mathrm{~mm}$, respectively. The aspect ratio and density are assumed constant across all ice bins. Small cloud droplets $\left(q_{c}\right)$ are not included in scattering calculations because they contribute negligibly to the backscattered power in the presence of ice crystals and precipitation-sized particles at $\mathrm{X}$ band. However, in addition to ice $q_{i}$, both large liquid drops $q_{r}$ (reaching diameters on the order of millimeters or less) and spherical aggregates $q_{s}$ are considered within the scattering calculations, where the density of $q_{s}$ is assumed as $\rho_{s}=100 \mathrm{~kg} \mathrm{~m}^{-3}$, as is typical of most current microphysical models (e.g., Lin et al. 1983; Thompson et al. 2008); however, snow is negligible within a majority of the results presented.

\section{Results}

Analyses of a control case of the shallow Arctic stratocumulus and sensitivity studies are presented to elucidate different components of the AHM and its impact on the calculation of dual-pol radar variables. Note that while the idealized dynamical forcings likely influence the evolutions of both the cloud system and the microphysics, the focus of this study is specifically on the microphysical characteristics of these simulations and their dual-pol signatures.

\section{a. Shallow Arctic stratocumulus: Control case}

The primary case discussed is the shallow (depth $\leq$ $600 \mathrm{~m}$ ) mixed-phase stratiform Arctic cloud layer described in section 2. Figure 2 depicts the evolution of horizontally averaged vertical profiles. The system is maintained primarily through LW radiative cooling (Fig. 2f). Liquid (Fig. 2a) and ice (Fig. 2b) mixing ratios do not exceed approximately 0.1 and $0.02 \mathrm{~g} \mathrm{~kg}^{-1}$ with maxima near 850 and $500 \mathrm{~m}$, respectively, which are consistent with the observations [see McFarquhar et al. (2011) and their Fig. 14 for details]. Ice particles consistently nucleate and grow between approximately 450 and $1000 \mathrm{~m}$, where the temperature suggests platelike growth (Fig. 2e) and $\mathrm{RH}_{i}>110 \%$ (Fig. 2b), with slightly larger concentrations at hour 4 when ice is introduced and within the upper 100-200 $\mathrm{m}$ of the liquid cloud layer (Fig. 2c). The ice population is initially dominated by dendrites with $\phi<0.1$ at hour 4 (Fig. 2e) and $\phi<0.3$ until just before hour 6 . This latter population accounts for a maximum in depositional growth (Figs. 3a,c) and hence $q_{i}$ (Fig. 2b). The dendritic crystals accumulate enough mass to fall through the subcloud layer $(<400 \mathrm{~m})$, where a portion of this mass sublimates when $\mathrm{RH}_{i}<100 \%$ (Fig. 3a). However, much of the mass sediments to the surface (Fig. 3b). This precipitation flux is also evident in the relatively constant $\phi$ with height prior to hour 6 , suggesting that many of the particles acquire sufficient terminal velocities to reach the surface prior to sublimation. Sublimation is expected to increase planar crystal $\phi$ toward unity. Following this initial period of rapid growth and sedimentation, the ice mass and growth rate reach a quasi-steady state, increasing steadily with the increase in liquid cloud depth and $q_{l}$ (Fig. 2a). The ice population remains dominated by approximately equal contributions of thin plates (i.e., $0.3<\phi<0.7)$ and dendrites (i.e., $\phi<0.3$; Fig. 3c). The ice number concentration remains relatively constant around $0.6-0.7 \mathrm{~L}^{-1}$ (Fig. 2c), where $\mathrm{RH}_{i}>105 \%$, and then decreases toward the surface as a result of the sublimation and sedimentation of ice particles. This result is consistent with the prescribed maximum of $N_{i}=$ $1 \mathrm{~L}^{-1}$ and provides a control on the simulations to avoid complications with varying ice activation rates.

Figures 2 and 4 indicate the contribution of ice particles to the simulated dual-pol output. The highest $Z_{\mathrm{H}}$ values correspond to the growth of the most dendritic particles $(\phi<0.1)$. Then, $Z_{\mathrm{H}}$ is relatively constant at approximately -25 to $-30 \mathrm{~dB} Z$, while $\phi$ remains below 0.3 . At this point, the total deposition (and hence $q_{i}$ ), sublimation, and sedimentation rates are maximized. 
(a) Liquid Mixing Ratio $\mathrm{q}_{\mathrm{c}}\left(\mathrm{g} \mathrm{kg}^{-1}\right)$

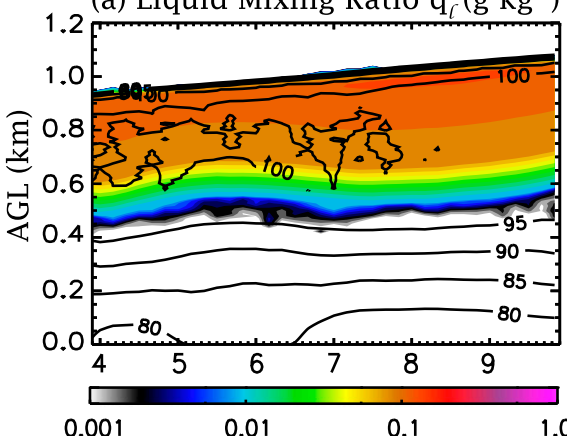

(d) Ice Density $\rho_{i}\left(\mathrm{~kg} \mathrm{~m}^{-3}\right)$

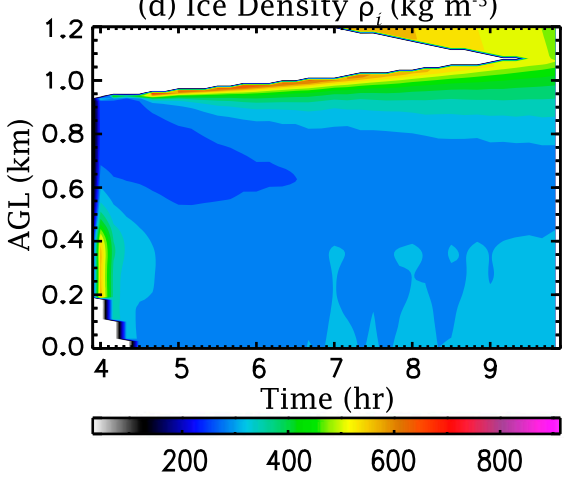

(b) Ice Mixing Ratio $\mathrm{q}$ ( $\mathrm{g} \mathrm{kg}^{-1}$ )

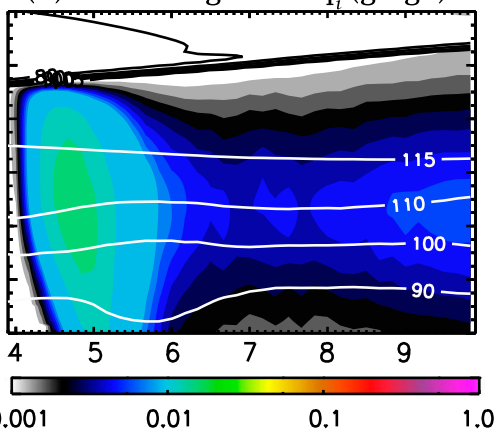

(e) Aspect Ratio $\Phi$

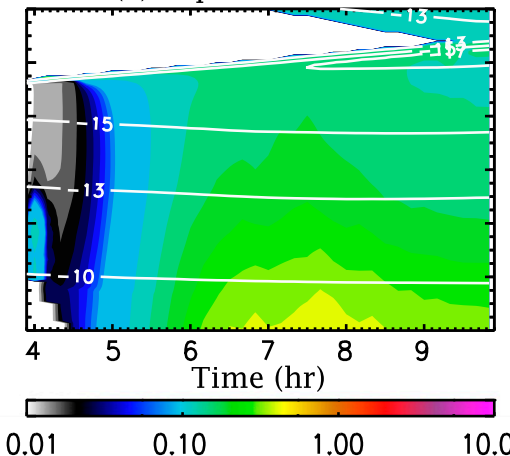

(c) Ice Concentration $\mathrm{n}_{(}\left(\mathrm{L}^{-1}\right)$

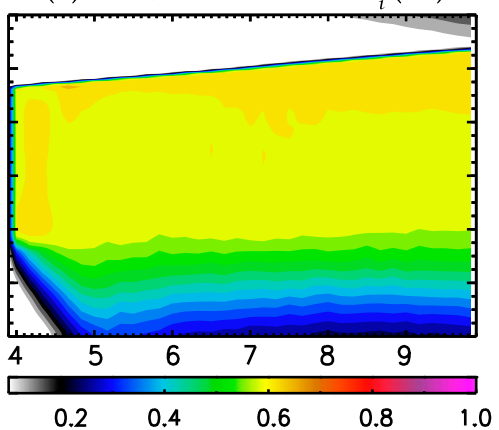

(f) LW effect on $\mathrm{d} \Theta / \mathrm{dt}\left(\mathrm{K} \mathrm{hr}^{-1}\right)$

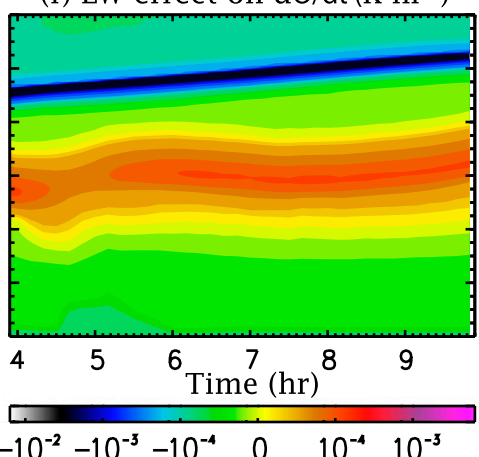

FIG. 2. Evolution of horizontally averaged vertical profiles of (a) liquid mixing ratio $q_{l}$ with relative humidity with respect to liquid $\mathrm{RH}_{l}$ overlaid (\%), (b) ice mixing ratio $q_{i}$ with relative humidity with respect to ice $\mathrm{RH}_{i}$ overlaid (\%), (c) ice number concentration $n_{i}$, (d) ice density $\rho_{i},(\mathrm{e})$ ice particle aspect ratio $\phi$ with temperature overlaid $\left({ }^{\circ} \mathrm{C}\right)$, and (f) $\mathrm{LW}$ radiative effect on potential temperature tendency $d \Theta / d t$ for a shallow Arctic stratus. Initial ice and cloud number concentrations are $N_{i}=1 \mathrm{~L}^{-1}$ and $N_{c}=200 \mathrm{~cm}^{-3}$, respectively; ice gamma distribution shape is $\nu=4$.

Sedimentation rates wane by hour 6 (Fig. 3b), and $q_{i}$ decreases by an order of magnitude, as reflected in the decreasing $Z_{\mathrm{H}}$ (Fig. 4a). Ice deposition and sedimentation reach steady states, increase slightly toward the end of the simulation, and are dominated by thin plates (Figs. 2e and 3c). Note that the $Z_{\mathrm{H}}$ values here are quite low (i.e., $<-40 \mathrm{~dB} Z$ ). Although these reflectivity values would not typically be observable by most X-band radars, the values are reasonable for small monomer crystals (and a lack of aggregates). For example, Fig. 5a illustrates results from a box model using three diagnosed ice crystal populations approximated from LES hours 4.5 (gold), 5 (cyan), and 8 (purple). The lower $Z_{\mathrm{H}}$ ranges as a function of $\phi$ and $\rho_{i}$ agree with the results from the fully coupled LES.

The $Z_{\mathrm{DR}}$ maximum and minimum mirror those in $Z_{\mathrm{H}}$. Here, $Z_{\mathrm{DR}}$ is a function of particle density $\rho_{i}$, but unlike $Z_{\mathrm{H}}, Z_{\mathrm{DR}}$ is also directly a function of shape $\phi$. Figure $6 \mathrm{a}$ illustrates the relationship between particle $\phi$ and $Z_{\mathrm{DR}}$ as a function of $\rho_{i}$ for monodispersed, uniformly filled spheroids of a given ice density. Similarly to Fig. 5, Fig. 6 was created using a simplified box model rather than the LES to easily assess the direct relationships among dualpol variables and $\phi$ and $\rho_{i}$. First, note the general trend toward increasing $Z_{\mathrm{DR}}$ with further deviation from $\phi=1$; this trend occurs for both aspect ratios greater than and less than unity. However, $Z_{\mathrm{DR}}$ is less dependent on shape when $\phi>1$. This is related to the geometry of the columnar particles (prolates), which tend to fall with their maximum dimension in the horizontal plane. With the maximum dimension aligned horizontally, columns may be randomly oriented in the azimuth, leading to different radar viewing angles relative to the maximum dimension and resulting in a decrease in $Z_{\mathrm{DR}}$ relative to what may otherwise be expected given a large $\phi$. In contrast, the maximum dimension of platelike particles (oblates, $\phi<1$ ) is visible from any side and thus generally results in larger $Z_{\mathrm{DR}}$. The dependency of $Z_{\mathrm{DR}}$ on ice density is also evident in Fig. $6 \mathrm{a}$, where $Z_{\mathrm{DR}}$ is reduced with decreasing $\rho_{i}$. A trend appears in Fig. 6 where the resulting dual-pol value is more sensitive to $\phi$ when $0.1<\phi<10$, whereas this sensitivity shifts to $\rho_{i}$ when $\phi<0.1$ and $\phi>10$. Note that $\rho_{i}$ and $\phi$ decrease from $920 \mathrm{~kg} \mathrm{~m}^{-3}$ and 1 , respectively, for nonspherical particles: both $\rho_{i}$ and $\phi$ are functions of the inherent growth ratio $(\delta)$, which is the ratio of the vapor deposition flux along the $a$ axis relative to the $c$ axis and is a direct function of temperature (e.g., 

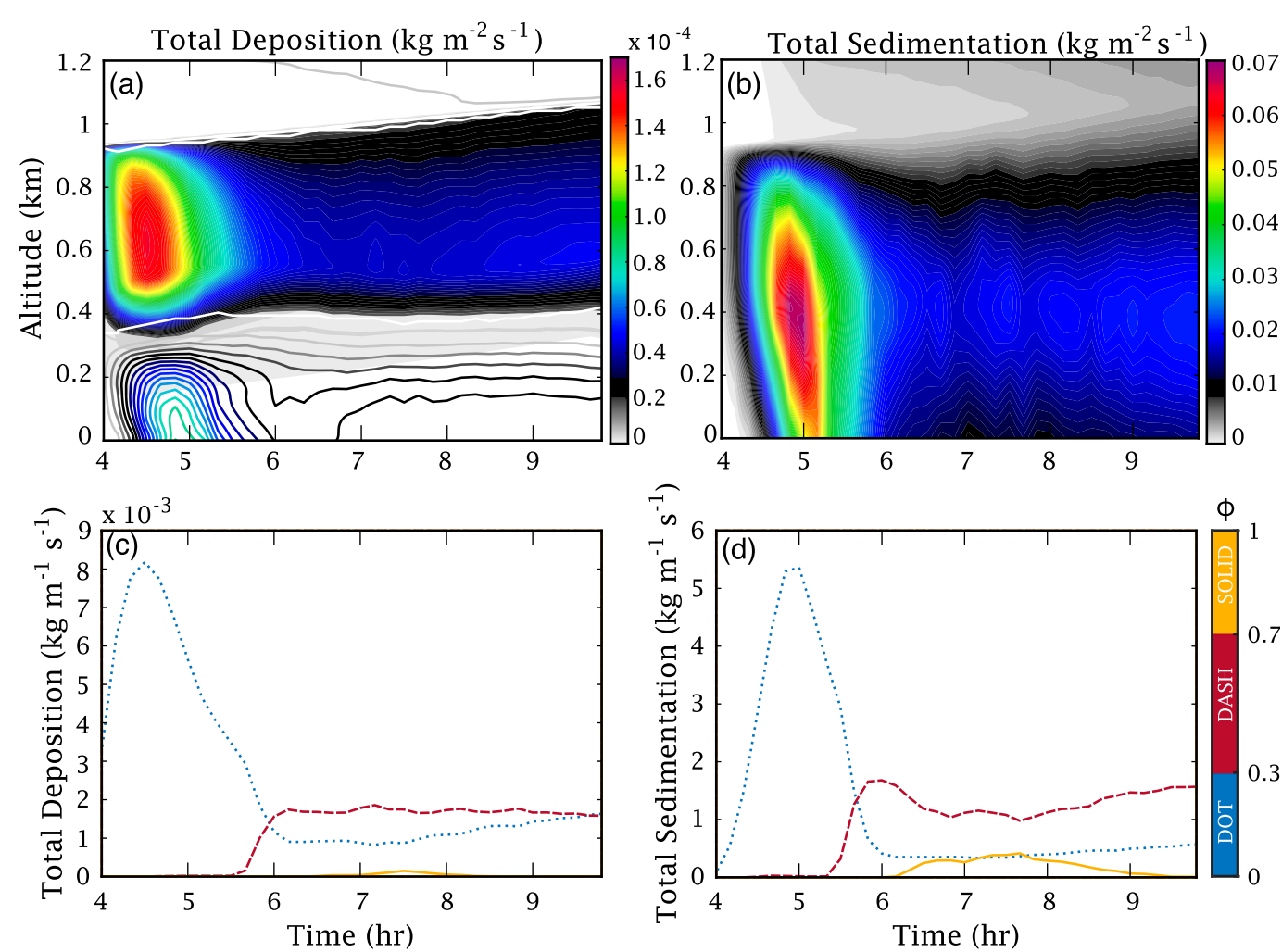

FIG. 3. Vertical time series of total (horizontally integrated) (a) deposition and (b) sedimentation rates. Sublimation is featured as unfilled contours in (a). Time series of total (vertically and horizontally integrated) (c) deposition and (d) sedimentation rates for three populations containing only crystals within $0<\phi<0.3$ (dendrites, dotted blue), $0.3<\phi<0.7$ (sectors and thin plates, dashed red), and $0.7<\phi<1.0$ (thick plates, solid gold).

Chen and Lamb 1994). Both $\rho_{i}$ and $\phi$ are directly proportional to $\delta$ when $\delta<1$ (plates) and inversely proportional when $\delta>1$ (columns); hence, they behave similarly as the particle deviates farther from spherical.

Further analysis of $Z_{\mathrm{DR}}$ is completed with cross sections at 0430 (Fig. 7, top) and 0800 UTC (bottom), the times during which the horizontally averaged $Z_{\mathrm{DR}}$ reaches its maximum and minimum values, respectively. The $Z_{\mathrm{DR}}$ maxima (0430 UTC) are located between 200 and $600 \mathrm{~m}$, and the minima (0800 UTC) are located below $400 \mathrm{~m}$. Lower $\phi(<0.1 ; 0430 \mathrm{UTC})$ are associated with higher $Z_{\mathrm{DR}}$ values $(>2 \mathrm{~dB})$ relative to 0800 UTC when $Z_{\mathrm{DR}}$ drops as $\phi \rightarrow 1$. The $\phi$ minima $(0.04$ and 0.4 ) during 0430 and 0800 UTC, respectively, occur within the liquid cloud layer, increasing at approximately $400 \mathrm{~m}$, where $\mathrm{RH}_{i}<100 \%$ and sublimation commences, reducing ice particle mass and increasing the particle aspect ratio toward one. Similarly, $Z_{\mathrm{DR}} \leq 1$ (0800 UTC) where $\rho_{i}$ is a minimum $\left(\leq 300 \mathrm{~kg} \mathrm{~m}^{-3}\right)$. Note that the $\rho_{i}$ contours more closely align with $Z_{\mathrm{DR}}$ when $\phi<0.1$ (0430 UTC), where $Z_{\mathrm{DR}}$ maxima correspond to maxima in $\rho_{i}\left(325 \mathrm{~kg} \mathrm{~m}^{-3}\right)$, whereas lower $\rho_{i}$ near cloud top $\left(275 \mathrm{~kg} \mathrm{~m}^{-3}\right)$ contribute to lower $Z_{\mathrm{DR}}$ and simulated particles represent dendrites that typically acquire lower effective densities. The $\phi$ contours align more closely with $Z_{\mathrm{DR}}$ when $\phi>0.1$ (0800 UTC), following the sensitivities apparent in Fig. 6 .

Because a relatively homogenous population of low-density $\left(\rho_{i}<300 \mathrm{~kg} \mathrm{~m}^{-3} ;\right.$ Fig. 2d) platelike $\left(0.01<\phi<0.5 ;\right.$ Fig. 2e) particles produces $\rho_{\mathrm{hv}}$ values $\geq 0.998$ (Fig. 6b, black line), it is no surprise that no notable $\rho_{\text {hv }}$ signature exists in Fig. 4c. The value of $\rho_{\text {hv }}$ only slightly deviates from 1.0 where $\phi$ is most extreme $^{1}$ and becomes more informative for situations in which multiple hydrometeor types are present or for simulations containing columnar particles, as will be shown in section $3 \mathrm{~b}$.

As with $\rho_{\mathrm{hv}}$ and $Z_{\mathrm{DR}}$, the largest $L_{\mathrm{DR}}$ values occur when habits are extreme $(\phi<0.3)$ and decrease when $\phi \rightarrow 1$ and for decreasing $q_{i}$. The large decrease in $L_{\mathrm{DR}}$ from hours 5-7 indicates the transition from dendritic

\footnotetext{
${ }^{1}$ The term extreme, when describing aspect ratios, indicates that the particle is highly nonspherical and is either dendritic $(\phi \ll 1)$ or needlelike $(\phi \gg 1)$.
} 

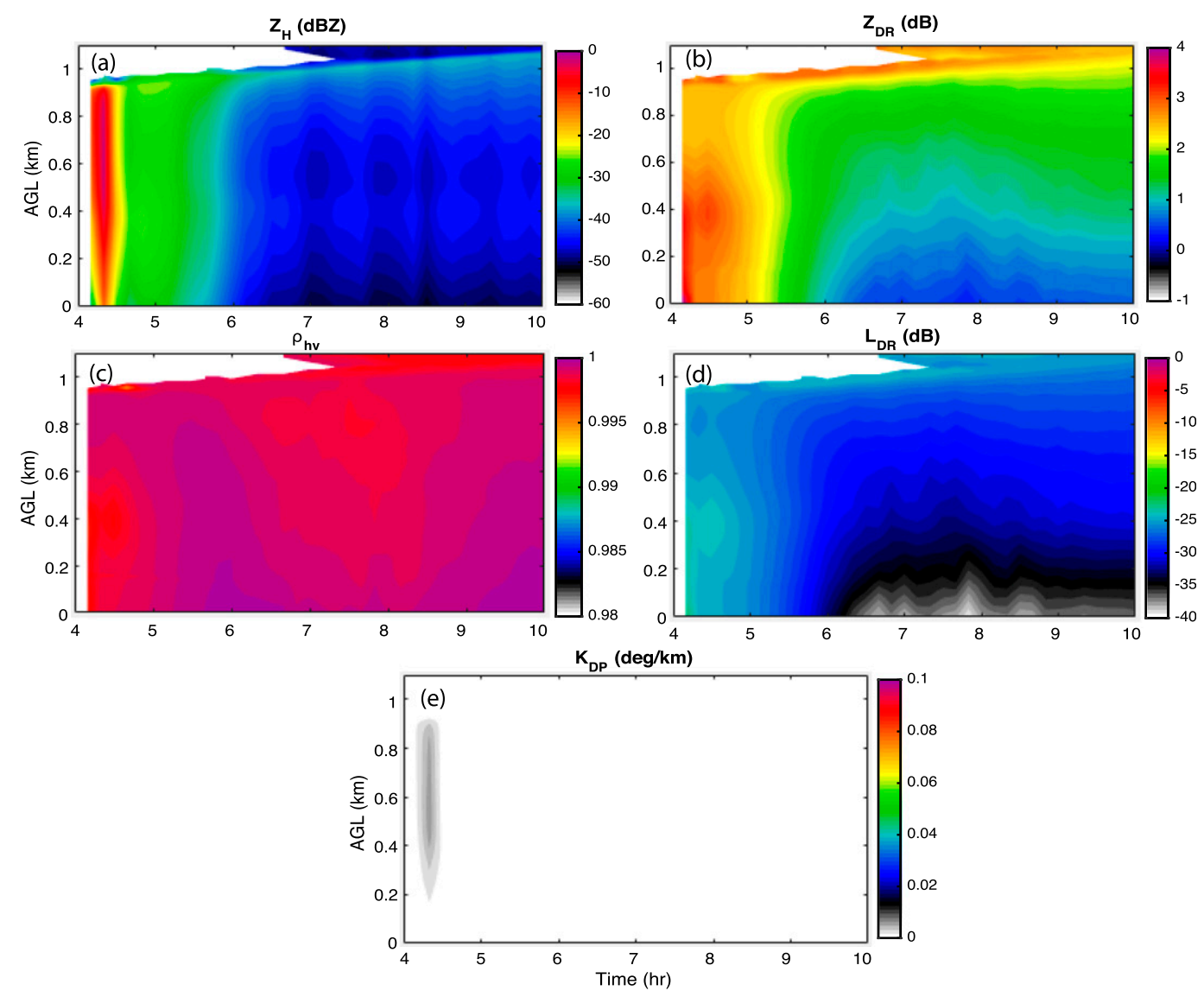

FIG. 4. Evolution of horizontally averaged vertical profiles of (a) reflectivity $Z_{\mathrm{H}}$, (b) differential reflectivity $Z_{\mathrm{DR}}$, (c) correlation coefficient $\rho_{\mathrm{hv}}$, (d) linear depolarization ratio $L_{\mathrm{DR}}$, and (e) specific differential phase $K_{\mathrm{DP}}$ for a shallow Arctic stratus case.

$(\phi<0.3)$ to less dendritic $(\phi>0.3)$ particles (Figs. 2e and $3 \mathrm{c}, \mathrm{d}$ ); it is within this range that $L_{\mathrm{DR}}$ is most sensitive to particle shape (Fig. $6 \mathrm{c}$ ).

Specific differential phase $K_{\mathrm{DP}}$ is enhanced for a large quantity (mass and/or number) or size of nonspherical particles and thus maximizes when highly nonspherical (dendritic) particles are found in large concentrations. Note that $K_{\mathrm{DP}}$ measures only nonspherical particles because isometric particles would result in zero differential phase shift, so only ice leads to enhancements because the rain droplets here are essentially drizzle and therefore spherical. Figure $5 \mathrm{~b}$ illustrates the $K_{\mathrm{DP}}$ dependency on $\phi, q_{i}, n_{i}$, and maximum dimension $D_{i}$. The $K_{\text {DP }}$ values are low $(<0.1)$ for each scenario depicted in Fig. 5b owing to the lower $q_{i}$ and $n_{i}$ values. Simulations with higher ice water contents and/or number would result in larger $K_{\mathrm{DP}}$, which is further explored in Part II. Additionally, $K_{\mathrm{DP}}$ is inversely proportional to the radar wavelength for Rayleigh scatterers; thus, simulations using higher-frequency radars may reveal larger values than those simulated at $\mathrm{X}$ band.
In summary, the simulations presented in this section of an idealized WRF-LES framework parse the microphysical contributions to dual-pol quantities. While some signatures may be lost as a result of the averaging of the results, domain averaging approximates a radar sampling volume given the relatively small size of the domain. Because of the simplicity of the case presented, only vapor-grown ice crystals contribute to the dual-pol output. Maxima and minima in all horizontally averaged variables- $Z_{\mathrm{H}}, Z_{\mathrm{DR}}, \rho_{\mathrm{hv}}, L_{\mathrm{DR}}$, and $K_{\mathrm{DP}}$-correspond to the fluctuations in $q_{i}$ and are strongly correlated with the evolution of $\phi$. Simplified box model simulations also confirm the dual-pol dependency on $\rho_{i}$ (and dielectric constant), though $\rho_{i}$ remains within $200<\rho_{i}<400 \mathrm{~kg} \mathrm{~m}^{-3}$ and so $\rho_{i}$ evolution is less prevalent in this simulation. The small reductions in $\rho_{\mathrm{hv}}$ indicate the negligible hydrometeor diversity in the given simulation (i.e., only the assumed distribution of canting angles for pristine ice crystals). Only briefly is $K_{\mathrm{DP}}$ enhanced for dendritic formation and growth, becoming negligible with decreases in $q_{i}, D_{i}$, and $n_{i}$. 


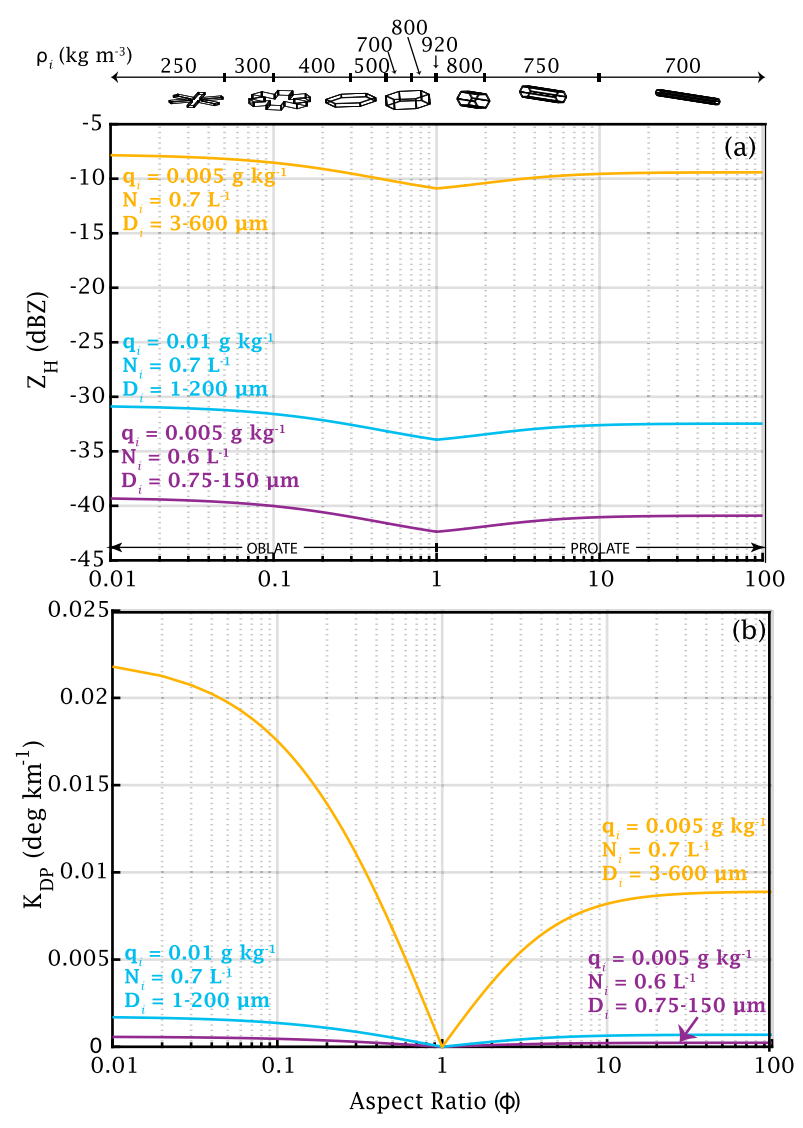

FIG. 5. Examples of box-model-forward-simulated (a) $Z_{\mathrm{H}}$ and (b) $K_{\mathrm{DP}}$ for three ice populations (as indicated) with ice density $\rho_{i}$ varying according to $\phi$. Also shown are cartoons of ice crystal types that are typical of the $\phi$ and $\rho_{i}$ ranges where they are placed.

\section{b. Sensitivity studies}

While the AHM provides for an ice vapor growth parameterization through the prediction of particle properties, the model does not consider complex nucleation mechanisms for liquid and ice. To avoid introducing complexities when simulating other processes, many studies exclude detailed nucleation methods (e.g., Solomon et al. 2009; Milbrandt et al. 2010; Ovchinnikov et al. 2014), which include their own range of uncertainties (e.g., Morrison et al. 2005; Fridlind et al. 2007; Solomon et al. 2015). Because $n_{i}$ and $n_{c}$ are relaxed to prescribed values $N_{i}$ and $N_{c}$, respectively, the evolutions of the predicted cloud layer and predicted dual-pol fields are sensitive to liquid and ice number assumptions. Moreover, a diagnostic approach to nucleation in a bulk parameterization requires information on mean initial ice particle nucleating size $r_{i}$ and gamma distribution shape $\nu$, which introduces more possible sensitivities. Though it is not ideal to diagnose nucleation mechanisms and parameters, sensitivities to these parameters provide insight into the behavior of the AHM and how microphysical processes may influence radar signatures.

\section{1) Sensitivity to $N_{i}$}

Figure 8 illustrates results found when comparing $N_{i}=1$ (solid black) and $10 \mathrm{~L}^{-1}$ (long dashed red) with $N_{c}=200 \mathrm{~cm}^{-3}$. (Note that these diagnosed values are upper limits for the nucleation relaxation method used, and the actual $n_{i}$ values will be slightly lower.) The $N_{i}=10 \mathrm{~L}^{-1}$ case initializes similarly to the $1 \mathrm{~L}^{-1}$ case with the rapid growth and subsequent sublimation and sedimentation of many dendritic particles. Hence, the larger $N_{i}$ yields a larger peak in $K_{\mathrm{DP}}$ (Fig. 8e), resulting from more numerous highly nonspherical particles, and a slightly higher $Z_{\mathrm{H}}$ maximum initially (Fig. 8a). However, because the available liquid is unchanged, the liquid cloud quickly dissipates by $4.5 \mathrm{~h}$ as a result of an increase in the Wegener-Bergeron-Findeisen (WBF) effect and is reestablished around hour 6 (Fig. 8g). As the liquid layer reforms, the larger number of particles increases the competition for vapor, limiting vapor diffusional growth and habit evolution, producing thicker plates and columns (Figs. 8h,i) with higher densities (Fig. 8j). The larger number of blockier crystals contributes more to $Z_{\mathrm{H}}$ than the smaller number of more pristine crystals and, in general, less to $Z_{\mathrm{DR}}$ and $L_{\mathrm{DR}}$ (Figs. 8b,c). Moreover, all else being equal, the larger $N_{i}$ results in a higher $q_{i}$ during growth and also larger losses in $q_{i}$ during sedimentation (faster fall speeds for more compact particles) and sublimation (larger sublimated ice density for spherical particles), both of which are reflected in enhancements in domain-averaged $q_{i}$ maxima and minima (Fig. 8f).

The larger ice number concentration affects the dynamical and microphysical evolutions within the simulation, ultimately influencing dual-pol variables. In this simulation, the rapid depletion of the liquid cloud just after ice initiation subsequently decreases $q_{i}$ (Figs. 8f,g and 9). At this point, there is a larger number $\left(6 \mathrm{~L}^{-1}\right)$ of small ice particles maintained aloft, while the largest particles sediment to the lowest levels and sublimate (not shown). Low-level sublimation moistens the subcloud layer and allows for the reestablishment of $q_{l}$ at lower levels (just above $200 \mathrm{~m}$ ), resulting in the development of a cloud with a base at $300 \mathrm{~m}$ and top at $800 \mathrm{~m}$ by the end of the simulation (Fig. 9). The temperature range within this second lower cloud layer is $\sim-10^{\circ} \leq T \leq-15^{\circ} \mathrm{C}$ (Fig. 9b), allowing for spherical, planar, and columnar particles. The formation of these particles results in a diverse population of ice crystals within the domain and thus an increased variability in $\phi$. Hence, results for the $10 \mathrm{~L}^{-1}$ case are shown for both oblate-only and 

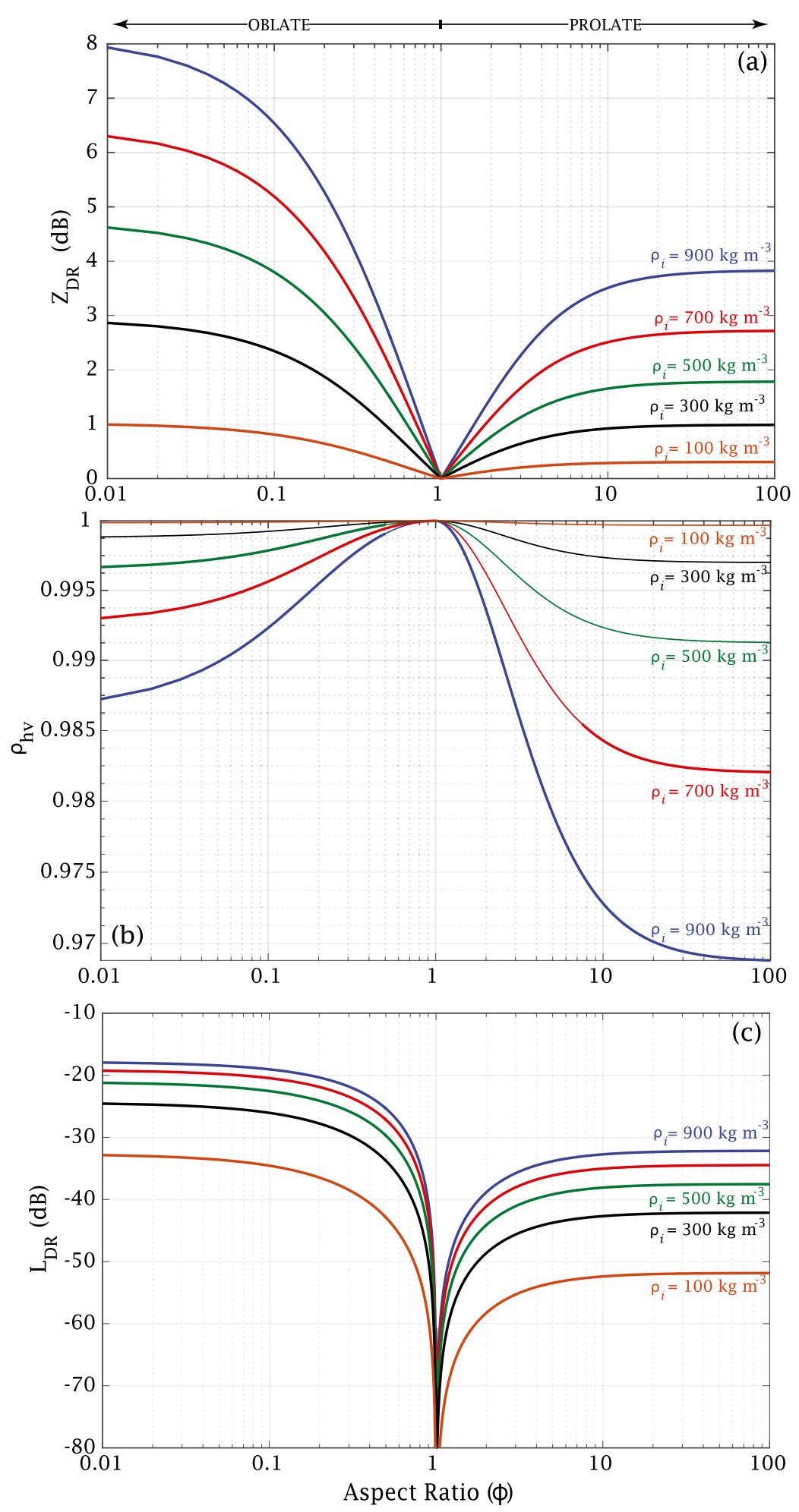

FIG. 6. Examples of box-model-forward-simulated (a) $Z_{\mathrm{DR}}$, (b) $\rho_{\mathrm{hv}}$, and (c) $L_{\mathrm{DR}}$ as a function of $\phi$ for constant ice density: $\rho_{i}=900$ (blue), 700 (red), 500 (green), 300 (black), and $100 \mathrm{~kg} \mathrm{~m}^{-3}$ (orange). Simplified box model assumptions: $q_{i}=0.01 \mathrm{~g} \mathrm{~m}^{-3}$ and $N_{i}=0.1 \mathrm{~L}^{-1}$ with crystal sizes ranging from $D_{i}=6$ to $100 \mu \mathrm{m}$. 

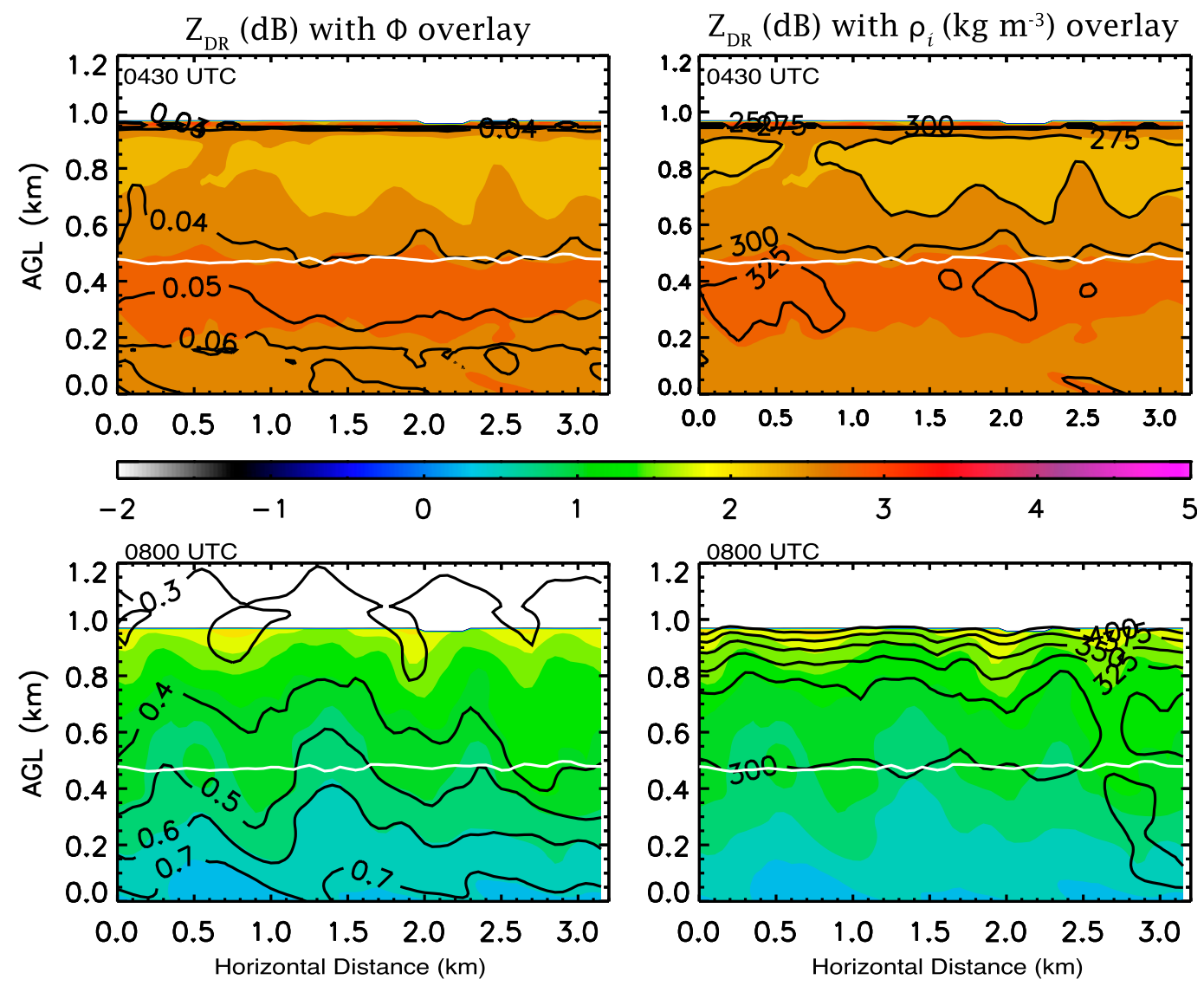

FIG. 7. Differential reflectivity $Z_{\mathrm{DR}}$ cross sections at (top) 0430 and (bottom) 0800 UTC for a shallow Arctic stratus case. Overlays of (left) $\phi$ in intervals of 0.01 at 0430 UTC and 0.1 at 0800 UTC and (right) $\rho_{i}$ in intervals of $25 \mathrm{~kg} \mathrm{~m}^{-3}$, both featured as black contours. The single white contour is representative of $q_{c}=0.001 \mathrm{~g} \mathrm{~kg}^{-1}$ and is considered cloud base.

prolate-only particles (short-dashed and dotted red lines, respectively). While the relatively homogeneous population of oblate particles aloft contributes little to the diversity of hydrometeor types (short-dashed red line), the columnar particles have aspect ratios close to and exceeding one (Fig. 8i), decreasing $\rho_{\mathrm{hv}}$ to values lower than the control simulation (Fig. 8d), which agrees with Fig. $6 \mathrm{~b}$, where $\rho_{\mathrm{hv}}$ is more sensitive to lower-density prolate particles. On average (longdashed red line), the population of ice particles in the $10 \mathrm{~L}^{-1}$ case is more diverse as a consequence of ice particles forming within different growth environments within a single domain.

Although the contribution of oblate particles enhances $Z_{\mathrm{DR}}$ and $L_{\mathrm{DR}}$ (short-dashed red lines in Figs. 8b and $8 \mathrm{c}$, respectively) in the $10 \mathrm{~L}^{-1}$ case, these enhanced signatures are overshadowed by the contribution of spheres and blocky columns to the volume when averaged over the domain. The domain-averaged time series presented here illustrates a useful conclusion: a situation in which multiple populations of particles are formed at different levels and then vertically advected within a cloud system could also produce observed dual-pol variables that would suggest more spherical particles, where in fact pristine particles may exist but are overshadowed or averaged out by crystals advected from a different growth environment into the same sampling volume (e.g., Oue et al. 2015; Part II). This example illustrates the benefit of analyzing forward-simulated dual-pol signatures with microphysical output.

\section{2) Sensitivity to $N_{c}$}

Investigations into whether the prescribed cloud droplet concentration $N_{c}$ may also influence ice microphysical properties are performed by comparing $N_{c}=200$ (Fig. 10, solid black) and $100 \mathrm{~cm}^{-3}$ (longdashed red) for $N_{i}=1 \mathrm{~L}^{-1}$. Reducing $N_{c}$ decreases $q_{l}$ by approximately $0.02 \mathrm{~g} \mathrm{~kg}^{-1}$ and results in larger liquid droplet sizes versus a larger number of smaller droplets as in the $N_{c}=200 \mathrm{~cm}^{-3}$ case. However, $N_{c}$ has little impact on all ice properties and growth for $N_{i}=1 \mathrm{~L}^{-1}$ 
Ice Concentration $\mathrm{N}_{i}$ Dependence
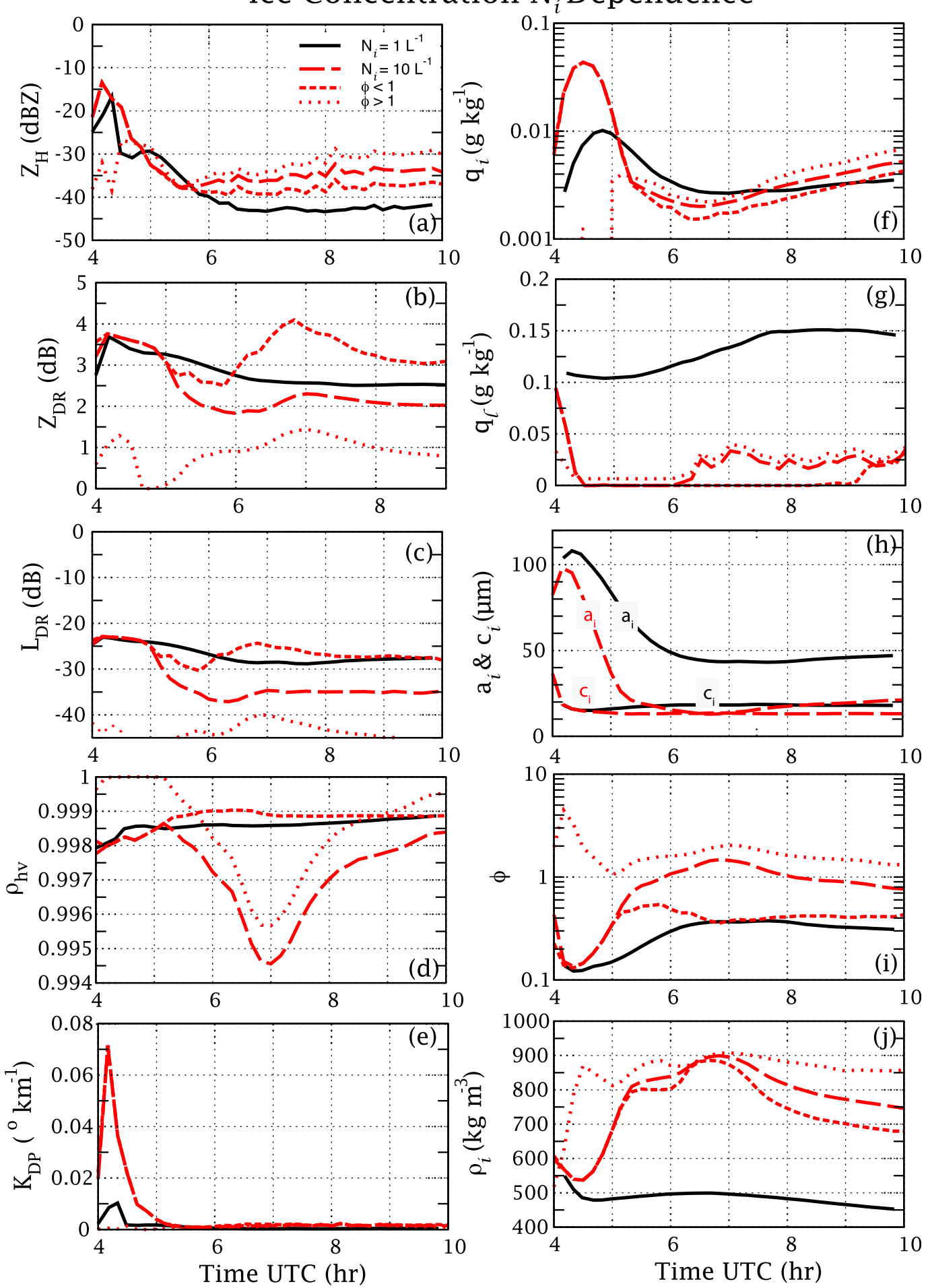

FIG. 8. Domain-averaged time series of (a) $Z_{\mathrm{H}}$, (b) $Z_{\mathrm{DR}}$, (c) $L_{\mathrm{DR}}$, (d) $\rho_{\mathrm{hv}}$, (e) $K_{\mathrm{DP}}$, (f) $q_{i}$, (g) $q_{l}$, (h) $a$ and $c$, (i) $\phi$, and (j) $\rho_{i}$ for $N_{i}=1$ (solid black) and $10 \mathrm{~L}^{-1}$ (long dashed red). Also shown are the results for plates only (short dashed red) and columns only (dotted red) for the $N_{i}=10 \mathrm{~L}^{-1}$ case. This separation is not shown for other cases as they only contain plates within the simulated time, and hence quantities are averaged over all particles. Here, $N_{c}=200 \mathrm{~cm}^{-3}, \nu=4$, and $r_{i}=1 \mu \mathrm{m} \mathrm{kg}^{-1}$. 

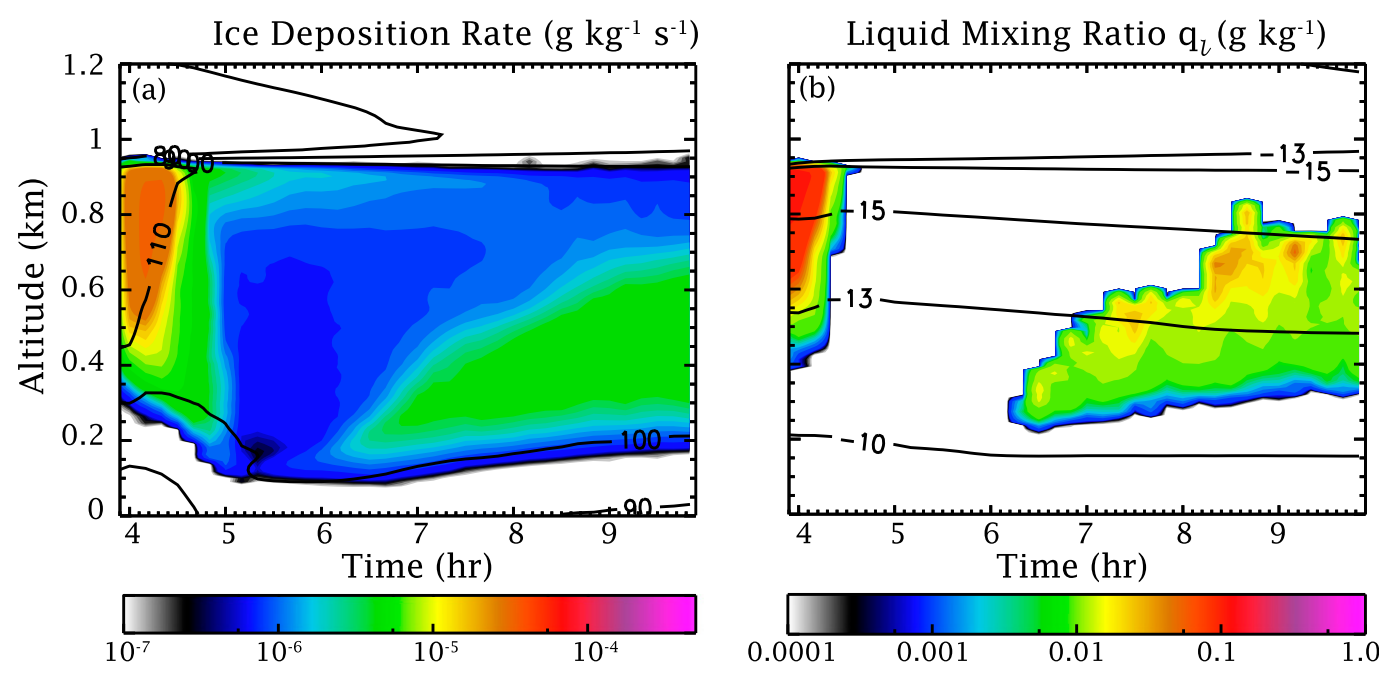

FIG. 9. Horizontally averaged time series of (a) ice depositional growth rate with $\mathrm{RH}_{i}$ overlaid and (b) $q_{l}$ with temperature $\left({ }^{\circ} \mathrm{C}\right)$ overlaid for $N_{i}=10 \mathrm{~L}^{-1}, \nu=4$, and $r_{i}=1 \mu \mathrm{m} \mathrm{kg}^{-1}$.

(Fig. 10c; effect on other properties is negligible, so not shown). Moreover, $q_{l}$ droplets do not reach sizes large enough to precipitate or substantially alter the growth environment and so also affect dual-pol variables negligibly (Figs. 10a,b; only $Z_{\mathrm{H}}$ and $Z_{\mathrm{DR}}$ are shown for brevity). The effect of the liquid droplet concentration is also minimal for the case where $N_{c}=300 \mathrm{~cm}^{-3}$ and $N_{i}=10 \mathrm{~L}^{-1}$ (not shown). Hence, it is speculated that as long as the environment remains saturated with respect to the liquid, there is little impact of $N_{c}$ for the case presented here.

\section{3) SENSITIVITY TO $\nu$}

The shape of the particle size distribution $\nu$ determines the dispersion of particle sizes relative to the assumed initial characteristic ice particle size $r_{n}=a_{n}=c_{n}$. Initially, smaller spherical particles acquire a larger vapor density gradient owing to larger curvature and thus grow more
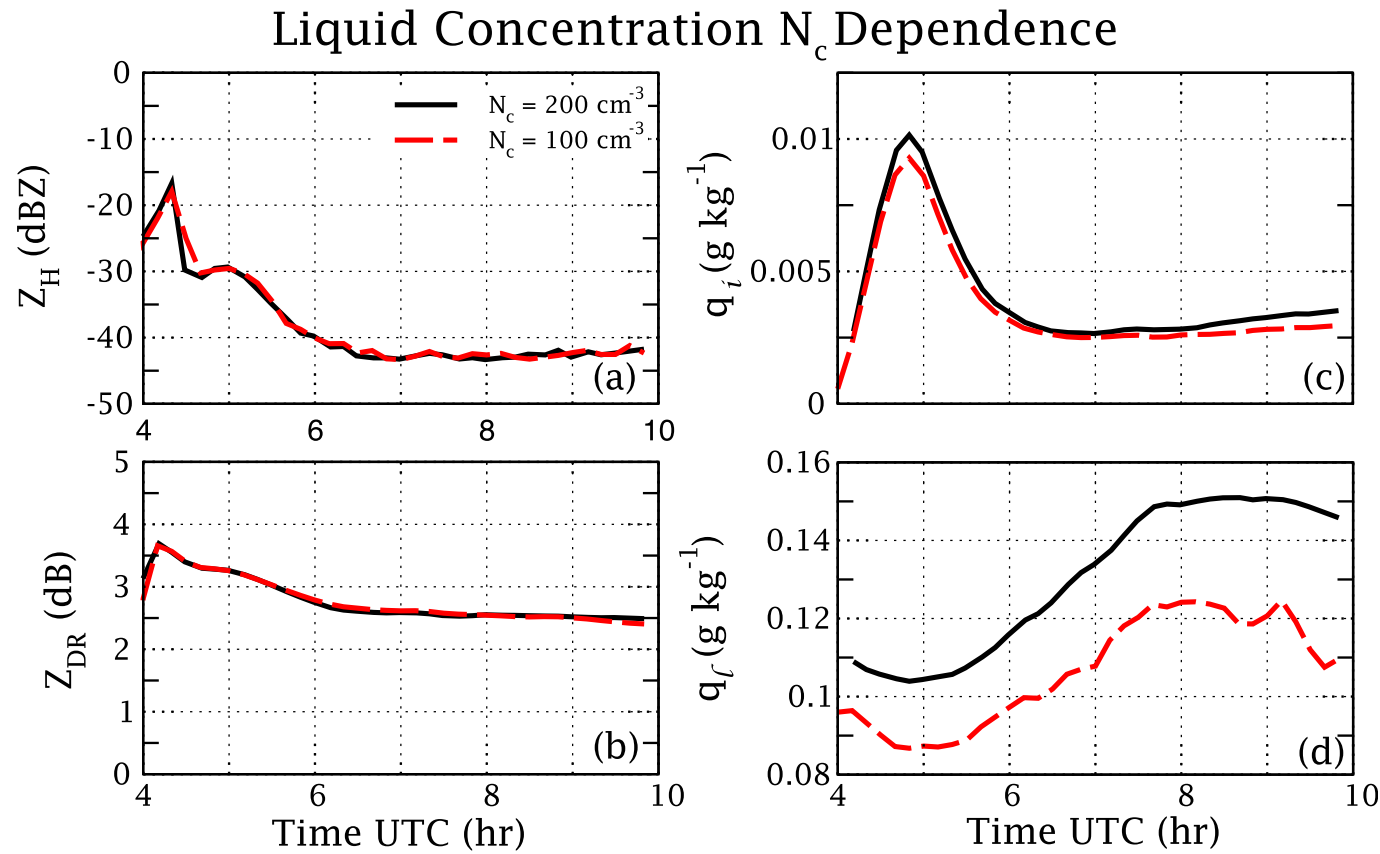

FIG. 10. Domain-averaged time series of (a) $Z_{\mathrm{H}}$, (b) $Z_{\mathrm{DR}}$, (c) $q_{i}$, and (d) $q_{l}$ for $N_{c}=200$ (solid black) and $100 \mathrm{~cm}^{-3}$ (long dashed red). The $\phi$ separation is not shown as the cases here only contain plates within the simulated time, and hence quantities are averaged over all particles. Here, $N_{i}=1 \mathrm{~L}^{-1}, \nu=4$, and $r_{i}=1 \mu \mathrm{m} \mathrm{kg}^{-1}$. 


\section{Distribution Shape $v$ Dependence}
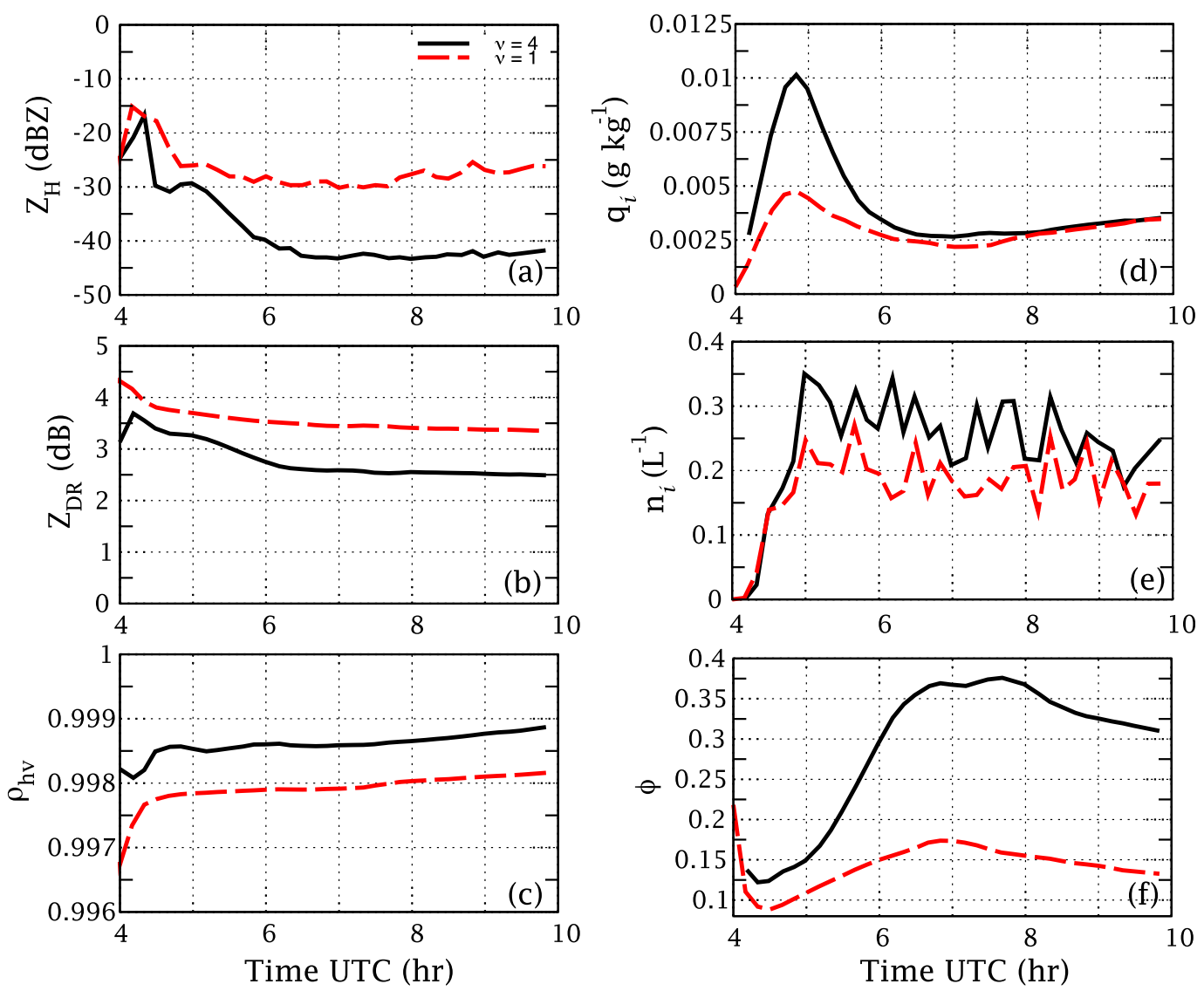

FIG. 11. Domain-averaged time series of (a) $Z_{\mathrm{H}}$, (b) $Z_{\mathrm{DR}}$, (c) $\rho_{\mathrm{hv}}$, (d) $q_{i}$, (e) $n_{i}$, and (f) $\phi$ for $\nu=4$ (solid black) and 1 (long dashed red). The $\phi$ separation is not shown as the cases here only contain plates within the simulated time, and hence quantities are averaged over all particles. Here, $N_{i}=1 \mathrm{~L}^{-1}, N_{c}=200 \mathrm{~cm}^{-3}$, and $r_{i}=1 \mu \mathrm{m} \mathrm{kg}^{-1}$.

quickly than initially larger spherical particles (e.g., Sheridan et al. 2009; Sulia and Harrington 2011). Hence, the distribution of particle sizes can potentially impact the rate of liquid depletion due to the WBF process, especially within lower ice saturation states. Two distribution shapes are simulated in Fig. 11 for dual-pol (Figs. 11a-c) and microphysical quantities (Figs. 11d-f): $\nu=1$, which is equivalent to an exponential distribution containing a spread covering a larger range of initial particle sizes, and $\nu=4$, which narrows the distribution to substantially reduce the number of the smallest (and largest) particles.

Because initially smaller ice particles grow through vapor diffusion more rapidly, the $\nu=1$ case contains more dendritic particles (Fig. 11f) with larger major characteristic axis lengths $\left(a_{n} \sim 100-250 \mu \mathrm{m}\right.$ versus $a_{n} \sim 40-100 \mu \mathrm{m}$ for $\nu=4$, on average). The particles in the $\nu=4$ distribution are less dendritic, with $\phi$ closer to one. However, while the dendritic growth of individual ice particles in the $\nu=1$ case is captured by larger $Z_{\mathrm{H}}$ values (Fig. 11a), this growth is not reflected in the averaged $q_{i}$ (Fig. 11d), where the $\nu=4$ case reaches higher values within the first $6 \mathrm{~h}$. This is due to the "vapor competition" effect, where increased individual particle growth in the $\nu=1$ case reduces the vapor available for other crystals in the population to nucleate and grow to substantial sizes, thereby reducing the simulated $n_{i}$ (Fig. 11e) initially and hence $q_{i}$. Recall that $N_{i}=1 \mathrm{~L}^{-1}$ is diagnosed for these simulations as a relaxation value, and temperature and saturation requirements must be met for nucleation to occur, and so a constant ice number is not guaranteed.

To further investigate the effect of $\nu$ on some microphysical and dual-pol quantities, vertical gradients in $q_{i}$, $a, Z_{\mathrm{H}}$, and $Z_{\mathrm{DR}}$ are presented in Fig. 12 for $\nu=4$ (left column) and 1 (right column). These gradients are calculated as $d q_{i} / d z=\left[q_{i}\left(z_{1}\right)-q_{i}\left(z_{2}\right)\right] /\left(z_{2}-z_{1}\right)$, where $z_{2}>z_{1}$. Hence, positive values imply that the quantity is increasing toward the surface; negative values imply that the quantity is decreasing toward the surface. 

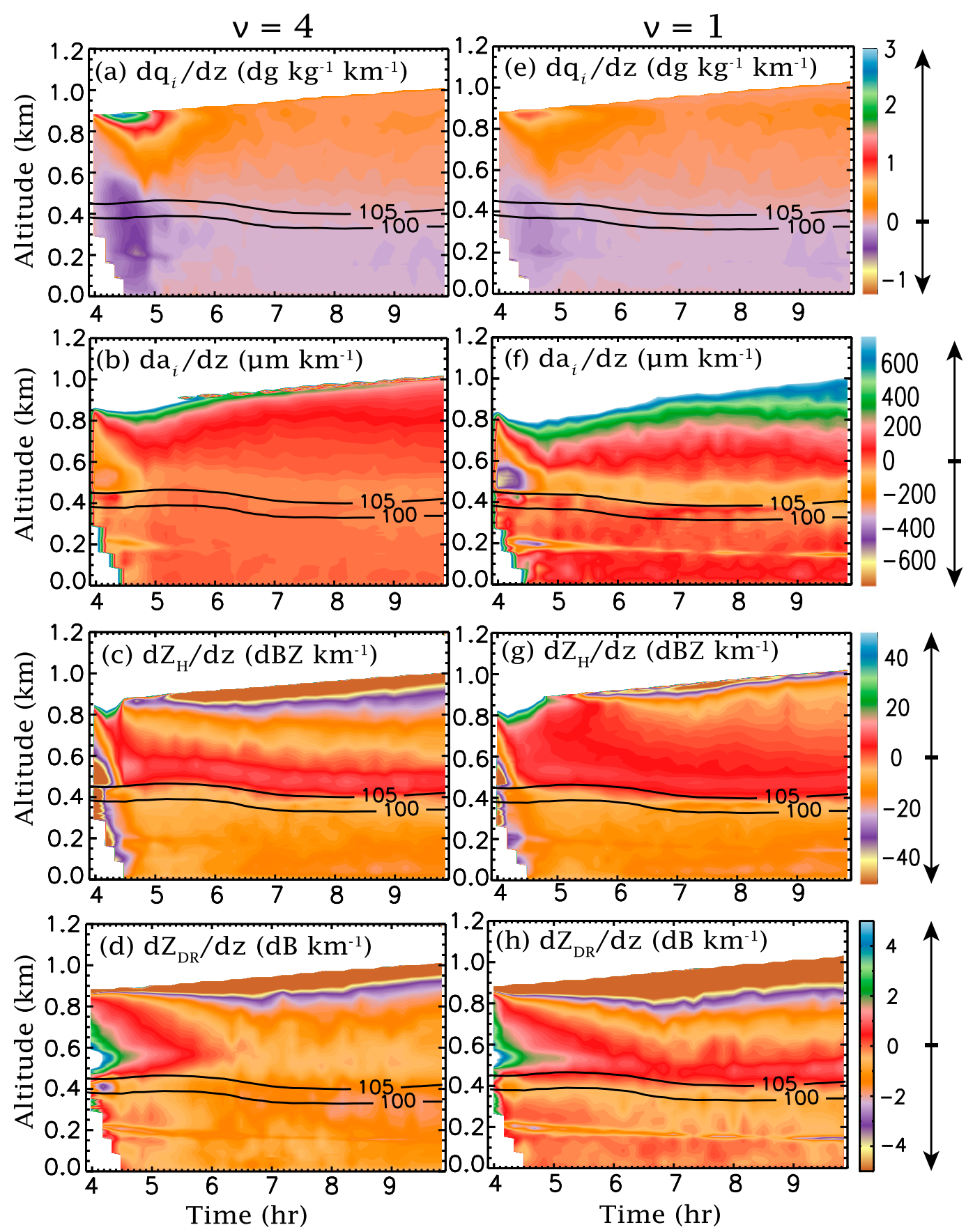

FIG. 12. Horizontally averaged time series of vertical gradients for (a),(e) $q_{i}$; (b),(f) $a$; (c), (g) $Z_{\mathrm{H}}$; and (d), (h) $Z_{\mathrm{DR}}$ for $v=$ (left) 4 and (right) 1 with $\mathrm{RH}_{i}=100$ and $105 \%$ overlays. Here, $N_{i}=1 \mathrm{~L}^{-1}$ and $N_{c}=200 \mathrm{~cm}^{-3}$. A positive gradient represents an increase in a given quantity toward the surface.

Trends in $q_{i}$ suggest larger depositional growth rates aloft and hence sedimentation from cloud top until approximately $550 \mathrm{~m}$ where ice growth subsides, reducing the sedimentation rates. The maximum (minimum) in $d q_{i} / d z$ for $\nu=4$ (Fig. 12a) is greater (less) than that for $\nu=1$ (Fig. 12e) within the first $2 \mathrm{~h}$, indicating that the population of particles sediment at similar rates, containing similar fall velocities and hence similar masses. In contrast, the $\nu=1$ case contains a larger number of initially smaller particles that accumulate more mass, increasing fall velocities and removing the quickly growing particles from the upper portion of the cloud: 
the broader distribution of initial particle sizes in the $\nu=1$ case results in a broader distribution of vapor growth rates, resulting in the "size sorting" of initially smaller particles from initially larger particles that grow more slowly and do not acquire extreme $\phi$. Particles with extreme $\phi$ are less dense, reducing fall velocities; however, this effect is secondary to the contributions of size and mass to terminal velocity. Hence, while the less dendritic particles are more compact, their sizes cannot discernibly compete with larger dendritic crystals (Fig. 11f). The larger dendritic particles "leave behind" the smaller and less dendritic particles aloft, increasing the vertical gradient in $a$ for $\nu=1$ (Fig. 12f) above $600 \mathrm{~m}$. This size sorting is less pronounced when the habit effect is reduced in the $\nu=4$ case, as reflected in $d a / d z$ and $d Z_{\mathrm{DR}} / d z$ values closer to $0 \mu \mathrm{m} \mathrm{km}^{-1}$ (Fig. 12b) and $0 \mathrm{~dB} \mathrm{~km}^{-1}$ (Fig. 12d), respectively.

Similar to the vertical gradients in $q_{i}$ and $a$, sizesorting and dendritic signatures are evident in $d Z_{\mathrm{H}} / d z$ and $d Z_{\mathrm{DR}} / d z$. The most dendritic particles grow until just above the sublimation layer at approximately $400 \mathrm{~m}$ when $d a / d z$ approaches $0 \mu \mathrm{m} \mathrm{km}^{-1}$ (Fig. 12f, bright orange band). The increasing $a$ toward the surface corresponds with a decrease in $Z_{\mathrm{DR}}$, indicating the reduction in $\rho_{i}$ experienced by dendritic particles, dropping to approximately $250 \mathrm{~kg} \mathrm{~m}^{-3}$ (not shown). This signature is less noticeable in the $\nu=4$ case where the ice population contains fewer dendrites. Moreover, the fact that $d q_{i} / d z$ and $d Z_{\mathrm{H}} / d z$ show only slight variations with height while the $d Z_{\mathrm{DR}} / d z$ and $d a / d z$ gradients are enhanced supports a relatively uniform vertical distribution of mass and hence a broader distribution in particle fall speed and habit. The more diverse population of ice crystals for $\nu=1$ is also reflected in lower values of $\rho_{\mathrm{hv}}$ (Fig. 11c), albeit only slightly given the low sensitivity of $\rho_{\text {hv }}$ to particles with $\phi<1$ (Fig. 6b).

Because the fall speeds of the dendritic particles in the $\nu=1$ case are reduced as they fall into the subcloud layer, they sediment more slowly before reaching the surface and hence are more likely to reside where $\mathrm{RH}_{i}<100 \%$. This results in the sublimation of ice particles below $400 \mathrm{~m}$, reducing $q_{i}$ and $n_{i}$, whereas the more compact particles that sediment to the lower levels within the $\nu=4$ case remain intact well below the subcloud layer, and so $q_{i}$ and $n_{i}$ are less affected. This is reflected in an increase in the vapor mixing ratio $q_{v}$ for the $\nu=1$ case by up to $0.25 \mathrm{~g} \mathrm{~kg}^{-1}$ relative to the $\nu=4$ case within the lowest $200 \mathrm{~m}$ of the domain (not shown).

Size sorting in the $\nu=1$ case also affects the parameterized nucleation rate. The larger and more pristine particles fall to lower levels and leave behind the smaller particles aloft. In addition, though the largest and most oblate particles fall quickly at first, their transition to pristine, dendritic-like particles (marked by the onset of decreasing $\rho_{i}$ and captured by the enhanced negative $d Z_{\mathrm{DR}} / d z$ signature) substantially reduces the fall speeds, "trapping" the particles in the nucleating region within the liquid cloud layer. Meanwhile, the $\nu=4$ case contains a population of more particles that fall at similar rates, leaving regions aloft with fewer particles. Nucleation is parameterized so that any grid cell that is within the nucleation criteria $\left(T<-5^{\circ} \mathrm{C}\right.$ and $\left.\mathrm{RH}_{i}>105 \%\right)$ is populated to relax toward the prescribed ice number concentration $\left(N_{i}=1 \mathrm{~L}^{-1}\right.$ in this case). Hence, the $\nu=4$ case nucleates more particles aloft upon sedimentation of previously grown crystals. Figure 11e illustrates the slight increase in $n_{i}$ as a result of this increased nucleation rate for the $\nu=4$ case. This increased nucleation aloft increases the domain-averaged $q_{i}$ (Fig. 11d).

\section{4) Sensitivity to $r_{i}$}

The final sensitivity is the prescribed average initial ice particle radius $r_{i}$ chosen to characterize the gamma distribution. Radii $r_{i}=1$ and $5 \mu \mathrm{m}$ are simulated (Fig. 13). The smaller radius ensures an overall smaller distribution of initially spherical particles (in contrast to the $\nu$ sensitivities, which alter the distribution spread over particle sizes). Because the particle populations as a whole are smaller in the $r_{i}=1 \mu \mathrm{m}$ case than those in the $r_{i}=5 \mu \mathrm{m}$ case, the initial size effect is apparent, and it is clear that initially smaller particles achieve greater $q_{i}$ (Fig. 13f) and become more pristine with lower $\phi$ and $\rho_{i}$ (Figs. 13i and 13j, respectively). These microphysical characteristics are reflected in the dual-pol variables where a slightly higher $Z_{\mathrm{H}}$ is returned for $r_{i}=1 \mu \mathrm{m}$ (Fig. 13a) as a result of the larger mass. The increased oblateness results in higher $Z_{\mathrm{DR}}, L_{\mathrm{DR}}$, and $K_{\mathrm{DP}}$, as well as a lower $\rho_{\text {hv }}$ (Figs. 13b-e). These results agree with expectations, similar to those presented in the previous section.

As with the $N_{i}$ sensitivity study, results are separated into contributions from prolates $(\phi>1$, dotted red line) and oblates $(\phi<1$, short-dashed red line) for the $r_{i}=5 \mu \mathrm{m}$ case only. Although prolate particles are formed, they appear to contribute insignificantly to the overall domain-averaged dual-pol and microphysical variables. Note that the averaged $q_{i}$ containing prolates exceeds that averaged over grid cells containing only oblates, but contributes little to the total $q_{i}$ (long-dashed red line in Fig. 13f): only a small number of grid cells containing columnar particles exists compared to those containing platelike particles. Hence, although the prolate particles acquire an appreciable mass, they only compose approximately $0.06 \%-6.0 \%$ of the total particle population $(0.07 \%-0.8 \%$ of grid cells). Thus, Fig. 13 
Initial Ice Radius $r_{i}$ Dependence
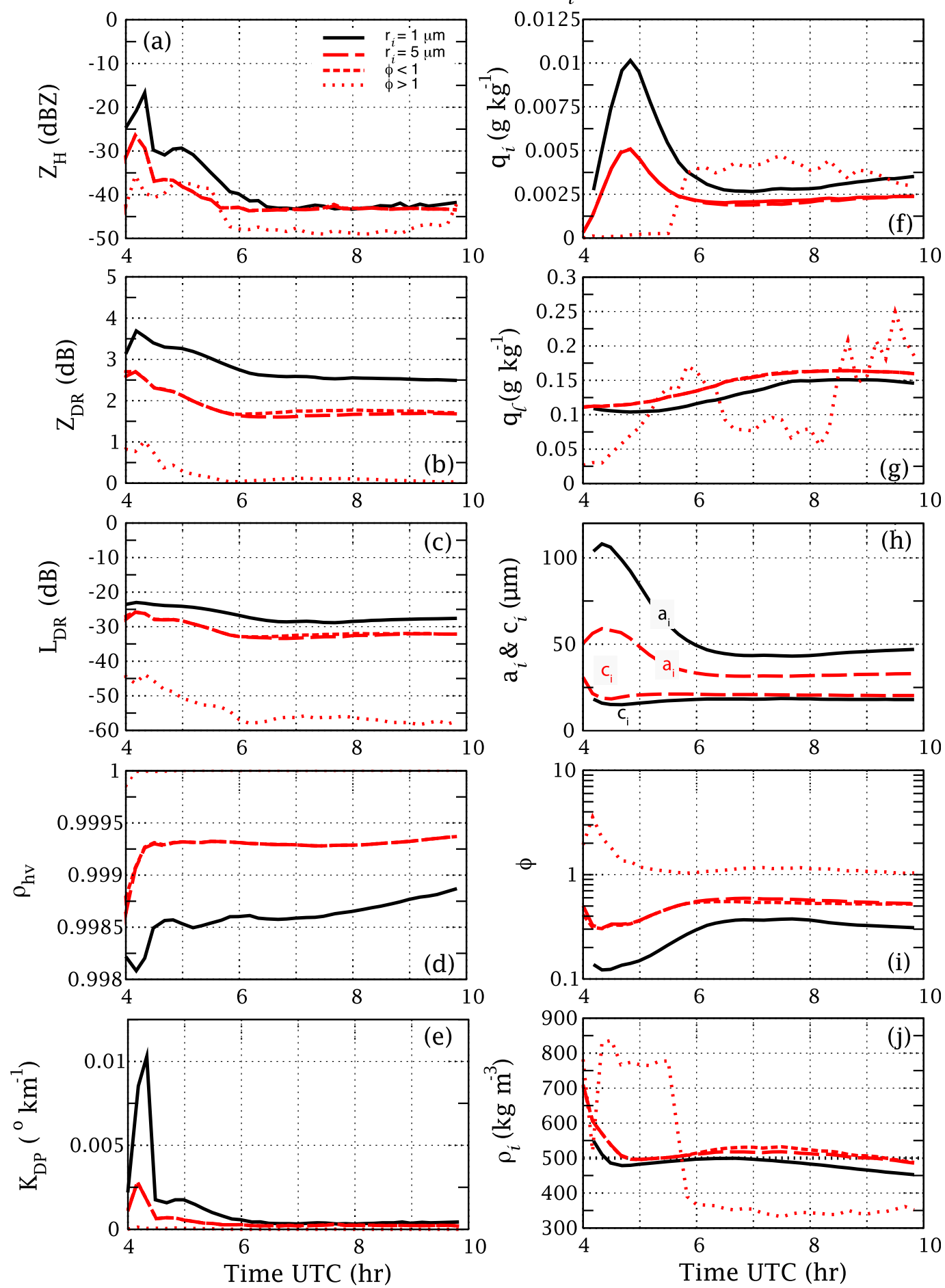

FIG. 13. Domain-averaged time series of (a) $Z_{\mathrm{H}}$, (b) $Z_{\mathrm{DR}}$, (c) $L_{\mathrm{DR}}$, (d) $\rho_{\mathrm{hv}}$, (e) $K_{\mathrm{DP}}$, (f) $q_{i}$, (g) $q_{l}$, (h) $a$ and $c$, (i) $\phi$, and (j) $\rho_{i}$ for $r_{i}=1$ (solid black) and $5 \mu \mathrm{m}$ (long dashed red). Averages of grid cells containing only plates (dashed red) and only columns (dotted red) are also shown for the $r_{i}=5 \mu \mathrm{m}$ case. This separation is not shown for other cases as they only contain plates within the simulated time, and hence quantities are averaged over all particles. Here, $N_{i}=1 \mathrm{~L}^{-1}, N_{c}=200 \mathrm{~cm}^{-3}$, and $\nu=4$. 
presents results that would be lost in a domain average: grid cells containing columnar particles attain a larger $q_{i}$ by hour 6 as a result of lower $n_{i}$ (and thus less competition for vapor) than plates. So, despite the larger $q_{i}$, the contribution of columnar particles to the simulated dualpol variables remains low because of their smaller $n_{i}$ compared to plates.

\section{Discussion and conclusions}

The unique ability of the AHM to predict particle properties, including shape and density, is combined with an offline forward operator to produce fields of simulated dual-pol variables. An evaluation of AHMforward-simulated dual-pol radar quantities in an idealized Arctic mixed-phase cloud is presented. Interpretation of dual-pol quantities is provided through microphysical model output. The ideal WRF-LES Arctic stratus case is chosen to capture the detailed vapor diffusional microphysics of the AHM without the complications of collection processes (e.g., riming and aggregation). Moreover, because all hydrometeors impact radar signatures, this case is chosen so that only pristine ice particle signatures are detected and not obfuscated by larger hydrometeors, such as aggregates or graupel. Although the majority of the observed cases in midlatitudes would include these complexities, the goal of this study is to examine AHM vapor-grown ice signatures in dual-pol variables in a comparatively simple environment. Additionally, LES provides a simplified framework to elucidate microphysical processes without evolving external thermodynamic and dynamic characteristics.

The initial case study presents a peak in the ice mass mixing ratio $q_{i}$ after particle initiation, followed by sedimentation and sublimation, leading to a minimum in $q_{i}$, which is then followed by a steady secondary increase in $q_{i}$. The minima and maxima in $Z_{\mathrm{H}}, Z_{\mathrm{DR}}$, and $L_{\mathrm{DR}}$ depend strongly on the initial growth of dendrites. Both $Z_{\mathrm{DR}}$ and $L_{\mathrm{DR}}$ are enhanced for a more extreme habit but decrease with a reduction in $\rho_{i}$, which is a parameterization of particle hollowing and branching. In addition, $K_{\mathrm{DP}}$ maximizes and $\rho_{\mathrm{hv}}$ minimizes with ice initiation when $\phi$ is extreme.

The sensitivity of microphysical and simulated radar fields to the diagnosed ice distribution and liquid concentration are also investigated. All else being equal, a larger ice number concentration $N_{i}$ results in the dissipation of the liquid cloud layer following ice initiation, which in turn results in rapid reductions in $q_{i}$ and $Z_{\mathrm{H}}$. Moreover, a larger $N_{i}$ encourages competition for available vapor (especially once the liquid has dissipated), causing a vertical distribution of particle habits, where smaller oblate particles remain aloft and a separate population of higher-density prolate ice crystals appears in a cloud layer formed at lower levels later in the simulation. The development of multiple crystal habits evolves the domain-average $\phi$ toward unity, reducing the domain-averaged $Z_{\mathrm{DR}}$ and $L_{\mathrm{DR}}$.

The effect of changing $N_{c}$ has little influence on both dual-pol and microphysical variables, including an increase in liquid droplet concentration $\left(300 \mathrm{~cm}^{-3}\right.$; not shown). Hence, from the results presented, it is apparent that, at least within the model, ice growth is relatively robust when the environment is supersaturated with respect to liquid and appears to be affected by the amount of available liquid only when the environment becomes subsaturated and the WBF effect is reduced.

There are not necessarily large differences in microphysical output to changes in the distribution shape $\nu$ (see Fig. 11, hours 6-8), but the effect on the forwardsimulated dual-pol variables can be substantial. For example, broadening the distribution enhances polarimetric signatures due to the nonlinear nonspherical growth of ice crystals. Moreover, the effect of appropriately defining $\nu$ has consequences for particle sizes and number indirectly due to fall velocities, size sorting, and premature sublimation, for example. Hence, it is suggested that future work consider utilizing bin or bin-bulk hybrid approaches or including an additional moment (i.e., Milbrandt et al. 2010) in detailed microphysical parameterizations so as to appropriately evolve $\nu$.

Finally, sensitivity to the initial mean ice nucleating size is examined, and results follow the physics described in Sulia and Harrington (2011). Initially smaller ice crystals grow faster and become more nonspherical than initially larger particles, resulting in enhancements in $q_{i}$ and $\phi$ and all polarimetric signatures. Moreover, increasing the ice particle size reduces the vapor diffusional growth rates and increases the fall speeds due to more compact particles relative to more pristine lowdensity particles. This allows the ice mass to sediment to lower levels, where temperatures support columnar growth. Here, the ice particle distribution can more easily "evolve away" from oblateness than if the particles were more pristine, as in the $r_{i}=1 \mu \mathrm{m}$ case. Although detailed nucleation is not considered in this study, the sensitivity to the initial nucleating size of ice crystals illustrates the potential need for accurate prognostic nucleation parameterizations coupled with detailed microphysics.

Though the simulations presented herein are idealized, they are illustrative of the complexities associated with ice microphysical parameterizations. Moreover, this work is a first step in utilizing an advanced ice particle growth scheme to simulate dual-pol variables that 
are available for comparison with polarimetric radar observations. The AHM is advantageous in that it prognoses the microphysical parameters (i.e., particle size, shape, and density) necessary to reasonably reproduce dual-pol radar variables and provides a basis for the interpretation of future, more realistic studies (e.g., Part II). Moreover, the interpretation of radar data using microphysical output from models and vice versa can be used to inform inferences made based on radar (or model) evaluation alone and provide more detailed insights into microphysical processes.

Acknowledgments. The authors would like to extend their sincerest gratitude to the three anonymous reviewers who provided the necessary comments and discussion to help shape this work into its current form. KS was supported through an appointment under the SUNY 2020 Initiative and under Award NA08OAR4320752 from the National Oceanic and Atmospheric Administration, U.S. Department of Commerce. The statements, findings, conclusions, and recommendations are those of the authors and do not necessarily reflect the views of the National Oceanic and Atmospheric Administration or the U.S. Department of Commerce. MK was supported by the National Science Foundation under Grant AGS1143948 and the Department of Energy under Grant DE-FG02-05ER64058.

\section{REFERENCES}

Andrić, J., M. R. Kumjian, D. S. Zrnić, J. M. Straka, and V. M. Melnikov, 2013: Polarimetric signatures above the melting layer in winter storms: An observational and modeling study. J. Appl. Meteor. Climatol., 52, 682-700, doi:10.1175/JAMC-D-12-028.1.

Avramov, A., and J. Harrington, 2010: Influence of parameterized ice habit on simulated mixed-phase Arctic clouds. J. Geophys. Res., 115, D24202, doi:10.1029/2009JD012108.

Baker, M. B., 1997: Cloud microphysics and climate. Science, 276, 1072-1078, doi:10.1126/science.276.5315.1072.

Bechini, R., L. Baldini, and V. Chandrasekar, 2013: Polarimetric radar observations in the ice region of precipitating clouds at C-band and X-band radar frequencies. J. Appl. Meteor. Climatol., 52, 1147-1169, doi:10.1175/JAMC-D-12-055.1.

Brandes, E. A., J. Vivekanandan, J. D. Tuttle, and C. J. Kessinger, 1995: A study of thunderstorm microphysics with multiparameter radar and aircraft observations. Mon. Wea. Rev., 123, 3129-3143, doi:10.1175/1520-0493(1995)123<3129:ASOTMW>2.0.CO;2.

Bringi, V., and V. Chandrasekar, 2001: Polarimetric Doppler Weather Radar: Principles and Applications. Cambridge University Press, $636 \mathrm{pp}$.

Browne, I. C., and N. P. Robinson, 1952: Cross-polarization of the radar melting band. Nature, 170, 1078-1079, doi:10.1038/ 1701078 b0.

Chandrasekar, V., R. Keränen, S. Lim, and D. Moisseev, 2013: Recent advances in classification of observations from dual polarization weather radars. Atmos. Res., 119, 97-111, doi:10.1016/j.atmosres.2011.08.014.
Chen, J., and D. Lamb, 1994: The theoretical basis for the parameterization of ice crystal habits: Growth by vapor deposition. J. Atmos. Sci., 51, 1206-1221, doi:10.1175/ 1520-0469(1994)051<1206:TTBFTP > 2.0.CO;2.

Colle, B. A., and C. F. Mass, 2000: The 5-9 February 1996 flooding event over the Pacific Northwest: Sensitivity studies and evaluation of the MM5 precipitation forecasts. Mon. Wea. Rev., 128, 593-617, doi:10.1175/1520-0493(2000)128<0593: TFFEOT $>2.0 . \mathrm{CO} ; 2$.

DeMott, P. J., and Coauthors, 2010: Predicting global atmospheric ice nuclei distributions and their impacts on climate. Proc. Natl. Acad. Sci. USA, 107, 11217-11222, doi:10.1073/ pnas.0910818107.

Doviak, R. J., and D. S. Zrnić, 1993: Doppler Radar and Weather Observations. 2nd ed. Academic Press, 562 pp.

Fovell, R. G., and H. Su, 2007: Impact of cloud microphysics on hurricane track forecasts. Geophys. Res. Lett., 34, L24810, doi:10.1029/2007GL031723.

Fridlind, A., A. Ackerman, G. McFarquhar, G. Zhang, M. Poellot, P. DeMott, A. Prenni, and A. Heymsfield, 2007: Ice properties of single-layer stratocumulus during the Mixed-Phase Arctic Cloud Experiment: 2. Model results. J. Geophys. Res., 112 , D24202, doi:10.1029/2007JD008646.

Fukuta, N., and T. Takahashi, 1999: The growth of atmospheric ice crystals: A summary of findings in vertical supercooled cloud tunnel studies. J. Atmos. Sci., 56, 1963-1979, doi:10.1175/ 1520-0469(1999)056<1963:TGOAIC > 2.0.CO;2.

Hall, W. D., 1980: A detailed microphysical model within a twodimensional dynamic framework: Model description and preliminary results. J. Atmos. Sci., 37, 2486-2507, doi:10.1175/ 1520-0469(1980)037<2486:ADMMWA>2.0.CO;2.

Harrington, J., T. Reisin, W. Cotton, and S. Kreidenweis, 1999: Cloud resolving simulations of Arctic stratus. Part II: Transition-season clouds. Atmos. Res., 51, 45-75, doi:10.1016/ S0169-8095(98)00098-2.

_, K. Sulia, and H. Morrison, 2013a: A method for adaptive habit prediction in bulk microphysical models. Part I: Theoretical development. J. Atmos. Sci., 70, 349-364, doi:10.1175/ JAS-D-12-040.1.

,-- , and,$- 2013 \mathrm{~b}$ : A method for adaptive habit prediction in bulk microphysical models. Part II: Parcel model corroboration. J. Atmos. Sci., 70, 365-376, doi:10.1175/ JAS-D-12-0152.1.

Heymsfield, A. J., G.-J. Van Zadelhoff, D. P. Donovan, F. Fabry, R. J. Hogan, and A. J. Illingworth, 2007: Refinements to ice particle mass dimensional and terminal velocity relationships for ice clouds. Part II: Evaluation and parameterizations of ensemble ice particle sedimentation velocities. J. Atmos. Sci., 64, 1068-1088, doi:10.1175/JAS3900.1.

Hong, S.-Y., J. Dudhia, and S.-H. Chen, 2004: A revised approach to ice microphysical processes for the bulk parameterization of clouds and precipitation. Mon. Wea. Rev., 132, 103-120, doi:10.1175/1520-0493(2004)132<0103:ARATIM>2.0.CO;2.

Hunter, I. M., 1954: Polarization of radar echoes from meteorological precipitation. Nature, 173, 165-166, doi:10.1038/ $173165 b 0$.

Jackson, R. C., and Coauthors, 2012: The dependence of ice microphysics on aerosol concentration in arctic mixed-phase stratus clouds during ISDAC and M-PACE. J. Geophys. Res., 117, D15207, doi:10.1029/2012JD017668.

Jensen, A., and J. Y. Harrington, 2015: Modeling ice crystal aspect ratio evolution during riming: A single particle growth model. J. Atmos. Sci., 72, 2569-2590, doi:10.1175/JAS-D-14-0297.1. 
— H. Morrison, and J. Milbrandt, 2017: Predicting ice shape evolution in a bulk microphysics model. J. Atmos. Sci., doi:10.1175/ JAS-D-16-0350.1, in press.

Jung, Y., G. Zhang, and M. Xue, 2008: Assimilation of simulated polarimetric radar data for a convective storm using the ensemble Kalman filter. Part I: Observation operators for reflectivity and polarimetric variables. Mon. Wea. Rev., 136, 2228-2245, doi:10.1175/2007MWR2083.1.

Kennedy, P. C., and S. A. Rutledge, 2011: S-band dual-polarization radar observations of winter storms. J. Appl. Meteor. Climatol., 50, 844-858, doi:10.1175/2010JAMC2558.1.

Key, J. R., P. Yang, B. A. Baum, and S. L. Nasiri, 2002: Parameterization of shortwave ice cloud optical properties for various particle habits. J. Geophys. Res., 107, doi:10.1029/2001JD000742.

Khvorostyanov, V. I., and K. Sassen, 1998: Cirrus cloud simulation using explicit microphysics and radiation. Part I: Model description. J. Atmos. Sci., 55, 1808-1821, doi:10.1175/ 1520-0469(1998)055<1808:CCSUEM > 2.0.CO;2.

Koenig, L., 1971: Numerical modeling of ice deposition. J. Atmos. Sci., 28, 226-237, doi:10.1175/1520-0469(1971)028<0226: $\mathrm{NMOID}>2.0 . \mathrm{CO} ; 2$.

Kogan, Y. L., and A. Belochitski, 2012: Parameterization of cloud microphysics based on full integral moments. J. Atmos. Sci., 69, 2229-2242, doi:10.1175/JAS-D-11-0268.1.

Korolev, A., and G. Isaac, 2003: Phase transformation of mixed-phase clouds. Quart. J. Roy. Meteor. Soc., 129, 19-38, doi:10.1256/ qj.01.203.

Kubar, T. L., D. L. Hartmann, and R. Wood, 2009: Understanding the importance of microphysics and macrophysics for warm rain in marine low clouds. Part I: Satellite observations. J. Atmos. Sci., 66, 2953-2972, doi:10.1175/2009JAS3071.1.

Kumjian, M. R., 2013a: Principles and applications of dualpolarization weather radar. Part I: Description of the polarimetric radar variables. J. Oper. Meteor., 1, 226-242, doi:10.15191/ nwajom.2013.0119.

— 2013b: Principles and applications of dual-polarization weather radar. Part II: Warm and cold season applications. J. Oper. Meteor., 1, 243-264, doi:10.15191/nwajom.2013.0120.

- 2013c: Principles and applications of dual-polarization weather radar. Part III: Artifacts. J. Oper. Meteor., 1, 265274, doi:10.15191/nwajom.2013.0121.

—, A. P. Khain, N. Benmoshe, E. Ilotoviz, A. Ryzhkov, and V. T. J. Phillips, 2014: The anatomy and physics of $Z_{\mathrm{DR}}$ columns: Investigating a polarimetric radar signature with a spectral bin microphysical model. J. Appl. Meteor. Climatol., 53, 1820-1843, doi:10.1175/JAMC-D-13-0354.1.

Lean, H. W., P. A. Clark, M. Dixon, N. M. Roberts, A. Fitch, R. Forbes, and C. Halliwell, 2008: Characteristics of highresolution versions of the Met Office Unified Model for forecasting convection over the United Kingdom. Mon. Wea. Rev., 136, 3408-3424, doi:10.1175/2008MWR2332.1.

Lin, Y., R. Farley, and H. Orville, 1983: Bulk parameterization of the snow field in a cloud model. J. Climate Appl. Meteor., 22, 10651092, doi:10.1175/1520-0450(1983)022<1065:BPOTSF>2.0.CO;2.

Lu, Y., E. E. Clothiaux, K. Aydin, G. Botta, and J. Verlinde, 2013: Modeling variability in dendritic ice crystal backscattering cross sections at millimeter wavelengths using a modified Rayleigh-Gans theory. J. Quant. Spectrosc. Radiat. Transfer, 131, 95-104, doi:10.1016/j.jqsrt.2013.05.008.

McFarquhar, G. M., and Coauthors, 2011: Indirect and SemiDirect Aerosol Campaign: The impact of Arctic aerosols on clouds. Bull. Amer. Meteor. Soc., 92, 183-201, doi:10.1175/ 2010BAMS2935.1.
Meyers, M., P. DeMott, and W. Cotton, 1992: New primary ice nucleation parameterizations in an explicit cloud model. J. Appl. Meteor., 31, 708-721, doi:10.1175/1520-0450(1992)031<0708: NPINPI $>2.0 . \mathrm{CO} ; 2$.

Milbrandt, J. A., and H. Morrison, 2013: Prediction of graupel density in a bulk microphysics scheme. J. Atmos. Sci., 70, 410429, doi:10.1175/JAS-D-12-0204.1.

, M. K. Yau, J. Mailhot, S. Bèlair, and R. McTaggart-Cowan, 2010: Simulation of an orographic precipitation even during IMPROVE-2. Part II: Sensitivity to the number of moments in the bulk microphysics scheme. Mon. Wea. Rev., 138, 625-642, doi:10.1175/2009MWR3121.1.

Mitchell, D. L., and A. J. Heymsfield, 2005: Refinements in the treatment of ice particle terminal velocities, highlighting aggregates. J. Atmos. Sci., 62, 1637-1644, doi:10.1175/JAS3413.1.

Mlawer, E. J., S. J. Taubman, P. D. Brown, M. J. Iacono, and S. A. Clough, 1997: Radiative transfer for inhomogeneous atmospheres: RRTM, a validated correlated-k model for the longwave. J. Geophys. Res., 102, 16 663-16 682, doi:10.1029/ 97JD00237.

Morrison, H., and W. W. Grabowski, 2008: Modeling supersaturation and subgrid-scale mixing with two-moment bulk warm microphysics. J. Atmos. Sci., 65, 792-812, doi:10.1175/ 2007JAS2374.1.

- M. Shupe, J. Pinto, and J. Curry, 2005: Possible roles of ice nucleation mode and ice nuclei depletion in the extended lifetime of Arctic mixed-phase clouds. Geophys. Res. Lett., 32, L18801, doi:10.1029/2005GL023614.

—, G. Thompson, and V. Tatarskii, 2009: Impact of cloud microphysics on the development of trailing stratiform precipitation in a simulated squall line: Comparison of one- and two-moment schemes. Mon. Wea. Rev., 137, 991-1007, doi:10.1175/2008MWR2556.1.

— , G. de Boer, G. Feingold, J. Harrington, M. Shupe, and K. Sulia, 2012: Resilience of persistent Arctic mixed-phase clouds. Nat. Geosci., 5, 11-17, doi:10.1038/ngeo1332.

- A. A. Jensen, J. Y. Harrington, and J. A. Milbrandt, 2016: Advection of coupled hydrometeor quantities in bulk cloud microphysics schemes. Mon. Wea. Rev., 144, 2809-2829, doi:10.1175/MWR-D-15-0368.1.

Newell, R. E., S. G. Geotis, M. L. Stone, and A. Fleisher, 1955: How round are raindrops? Proc. Fifth Weather Radar Conf., Asbury Park, NJ, Amer. Meteor. Soc., 261-268.

Ono, A., 1969: The shape and riming properties of ice crystals in natural clouds. J. Atmos. Sci., 26, 138-147, doi:10.1175/ 1520-0469(1969)026<0138:TSARPO >2.0.CO;2.

Oreopoulos, L., and H. W. Barker, 1999: Accounting of the subgrid-scale cloud variability in a multi-layer $1 \mathrm{~d}$ solar radiative transfer algorithm. Quart. J. Roy. Meteor. Soc., 125, 301330, doi:10.1002/qj.49712555316.

Oue, M., M. R. Kumjian, Y. Lu, Z. Jiang, E. E. Clothiaux, J. Verlinde, and K. Aydin, 2015: X-band polarimetric and Ka-band Doppler spectral radar observations of a graupelproducing Arctic mixed-phase cloud. J. Appl. Meteor. Climatol., 54, 1335-1351, doi:10.1175/JAMC-D-14-0315.1.

Ovchinnikov, M., and Coauthors, 2014: Intercomparison of largeeddy simulations of Arctic mixed-phase clouds: Importance of ice size distribution assumptions. J. Adv. Model. Earth Syst., 6, 223-248, doi:10.1002/2013MS000282.

Passarelli, R. E., 1978: An approximate analytical model of the vapor deposition and aggregation of snowflakes. J. Atmos. Sci., 35, 118-124, doi:10.1175/1520-0469(1978)035<0118: AAAMOT $>2.0 . \mathrm{CO} ; 2$. 
Reisner, J., R. Rasmussen, and R. Bruintjes, 1998: Explicit forecasting of supercooled liquid water in winter storms using the MM5 mesoscale model. Quart. J. Roy. Meteor. Soc., 124, 10711107, doi:10.1002/qj.49712454804.

Ryzhkov, A. V., T. J. Schuur, D. W. Burgess, P. L. Heinselman, S. E. Giangrande, and D. S. Zrnić, 2005: The Joint Polarization Experiment: Polarimetric rainfall measurements and hydrometeor classification. Bull. Amer. Meteor. Soc., 86, 809-824, doi:10.1175/BAMS-86-6-809.

—, M. Pinsky, A. Pokrovsky, and A. Khain, 2011: Polarimetric radar observation operator for a cloud model with spectral microphysics. J. Appl. Meteor. Climatol., 50, 873-894, doi:10.1175/2010JAMC2363.1.

Saleeby, S. M., and W. R. Cotton, 2008: Binned approach to cloud-droplet riming implemented in a bulk microphysics model. J. Appl. Meteor. Climatol., 47, 694-703, doi:10.1175/ 2007JAMC1664.1.

Sheridan, L., J. Harrington, D. Lamb, and K. Sulia, 2009: Influence of ice crystal aspect ratio on the evolution of ice size spectra during vapor depositional growth. J. Atmos. Sci., 66, 37323743, doi:10.1175/2009JAS3113.1.

Skamarock, W. C., and Coauthors, 2008: A description of the Advanced Research WRF version 3. NCAR Tech. Note NCAR/TN-475+STR, 113 pp., doi:10.5065/D68S4MVH.

Solomon, A., M. Shupe, P. Persson, and H. Morrison, 2009: Investigation of microphysical parameterizations of snow and ice in Arctic clouds during M-PACE through model observation comparisons. Mon. Wea. Rev., 137, 3110-3128, doi:10.1175/2009MWR2688.1.

-, G. Feingold, and M. Shupe, 2015: The role of ice nuclei recycling in the maintenance of cloud ice in Arctic mixedphase stratocumulus. Atmos. Chem. Phys., 15, 11 727-11 761, doi:10.5194/acpd-15-11727-2015.

Sulia, K. J., and J. Y. Harrington, 2011: Ice aspect ratio influences on mixed-phase clouds: Impacts on phase partitioning in parcel models. J. Geophys. Res., 116, D21309, doi:10.1029/ 2011JD016298.

__ and M. R. Kumjian, 2017: Simulated polarimetric fields of ice vapor growth using the adaptive habit model. Part II: A case study from the FROST experiment. Mon. Wea. Rev., 145, 2303-2323, doi:10.1175/MWR-D-16-0062.1.

, J. Y. Harrington, and H. Morrison, 2013: A method for adaptive habit prediction in bulk microphysical models. Part III: Applications and studies within a two-dimensional kinematic model. J. Atmos. Sci., 70, 3302-3320, doi:10.1175/JAS-D-12-0316.1.

-, H. Morrison, and J. Harrington, 2014: Dynamical and microphysical evolution during mixed-phase cloud glaciation simulated using the bulk adaptive habit prediction model. J. Atmos. Sci., 71, 4158-4180, doi:10.1175/JAS-D-14-0070.1.
Takano, Y., and K.-N. Liou, 1989: Solar radiative transfer in cirrus clouds. Part I: Single-scattering and optical properties of hexagonal ice crystals. J. Atmos. Sci., 46, 3-19, doi:10.1175/ 1520-0469(1989)046<0003:SRTICC >2.0.CO;2.

Thompson, G., R. Rasmussen, and K. Manning, 2004: Explicit forecasts of winter precipitation using an improved bulk microphysics scheme. Part I: Description and sensitivity analysis. Mon. Wea. Rev., 132, 519-542, doi:10.1175/ 1520-0493(2004)132<0519:EFOWPU>2.0.CO;2.

- P. Field, R. Rasmussen, and W. Hall, 2008: Explicit forecasts of winter precipitation using an improved bulk microphysics scheme. Part II: Implementation of a new snow parameterization. Mon. Wea. Rev., 136, 5095-5115, doi:10.1175/ 2008MWR2387.1.

Thurai, M., and V. N. Bringi, 2005: Drop axis ratios from a 2D video disdrometer. J. Atmos. Oceanic Technol., 22, 966-978, doi:10.1175/JTECH1767.1.

Vivekanandan, J., D. S. Zrnić, S. M. Ellis, R. Oye, A. V. Ryzhkov, and J. Straka, 1999: Cloud microphysics retrieval using S-band dual-polarization radar measurements. Bull. Amer. Meteor. Soc., 80, 381-388, doi:10.1175/1520-0477(1999)080<0381: CMRUSB $>2.0 . \mathrm{CO} ; 2$.

Walko, R., W. Cotton, M. Meyers, and J. Harrington, 1995: New RAMS cloud microphysics parameterization. Part I: The single-moment scheme. Atmos. Res., 38, 29-62, doi:10.1016/ 0169-8095(94)00087-T.

Weisman, M. L., C. Davis, W. Wang, K. W. Manning, and J. B. Klemp, 2008: Experiences with 0-36-h explicit convective forecasts with the WRF-ARW model. Wea. Forecasting, 23, 407-437, doi:10.1175/2007WAF2007005.1.

Wexler, R., 1955: An evaluation of the physical effects of the melting layer. Proc. Fifth Weather Radar Conf., Asbury Park, NJ, Amer. Meteor. Soc., 329-334.

Woods, C., M. Stoelinga, and J. Locatelli, 2007: The IMPROVE-1 storm of 1-2 February 2001. Part III: Sensitivity of a mesoscale model simulation to the representation of snow particle types and testing of a bulk microphysical scheme with snow habit prediction. J. Atmos. Sci., 64, 3927-3948, doi:10.1175/ 2007JAS2239.1.

Yamaguchi, T., and G. Feingold, 2012: Technical note: Large-eddy simulation of cloudy boundary layer with the Advanced Research WRF Model. J. Adv. Model. Earth Syst., 4, M09003, doi:10.1029/2012MS000164.

Zhang, C., and J. Y. Harrington, 2014: Including surface kinetic effects in simple models of ice vapor diffusion. J. Atmos. Sci., 71, 372-390, doi:10.1175/JAS-D-13-0103.1.

Zrnić, D. S., and A. V. Ryzhkov, 1999: Polarimetry for weather surveillance radars. Bull. Amer. Meteor. Soc., 80, 389-406, doi:10.1175/1520-0477(1999)080<0389:PFWSR>2.0.CO;2. 